\title{
Conflicts of interest, information provision, and competition in the financial services industry*
}

\author{
Patrick Bolton $^{a *}$, Xavier Freixas ${ }^{b}$, Joel Shapiro ${ }^{c}$ \\ ${ }^{a}$ Columbia University, 804 Uris Hall, New York NY 10027, USA \\ ${ }^{b}$ Universitat Pompeu Fabra, Ramon Trias Fargas 25-27, 08005 Barcelona, \\ Spain \\ ${ }^{c}$ Universitat Pompeu Fabra, Ramon Trias Fargas 25-27, 08005 Barcelona, \\ Spain
}

Received 23 December 2004; received in revised format 12 May 2005; accepted 16 June 2005

\begin{abstract}
In some markets sellers have better information than buyers over which products best serve a buyer's needs. Depending on the market structure, this may lead to conflicts of interest in the provision of information by sellers. This paper studies this issue in the market for financial services. The analysis presents a new model of competition between banks, where price competition influences the ensuing incentives for truthful information revelation. We also compare conflicts of interest in two different firm structures, specialized banking and one-stop banking.

JEL Classifications: D43, D82, G20, L15

Keywords: Conflicts of interest, information provision, one-stop banks, financial advice

*Financial support from the Fondation Banque de France and Barcelona Economics (CREA) is gratefully acknowledged. Shapiro also acknowledges financial support from DGES and FEDER under BEC2003-00412.We thank Ricardo Fuentes and Judit Montoriol for their research assistance. We give special thanks to Douglas Diamond and David Blair for their detailed suggestions. We are also grateful to Yeon-Koo Che, Fabrizio Germano, Joseph Harrington, Sjaak Hurkens, Edi Karni, Giancarlo Spagnolo, an anonymous referee, and audiences at the Agency Problems and Conflicts of Interest in Financial Intermediaries conference held at Ohio State University, the Banque de France, Boston University, Columbia University, the Duke-Northwestern-Texas IO Theory Conference, Johns Hopkins, the University of Wisconsin-Madison, the Econometric Society NASM 2003 and NAWM 2004 meetings, and the European Finance Association 2003 meetings for helpful

*Corresponding author contact information:pb2208@columbia.edu
\end{abstract} comments. 


\section{Introduction}

This paper examines the provision of information by sellers of financial services to customers. The issue of information provision is timely, as the banking industry evolves from the traditional business of financial intermediation towards a fee-based industry in which information is crucial in providing customers more added value. In a departure from the standard finance literature, we make the assumption that some investors are partially uninformed in the sense that they don't know which financial product best suits their needs. This assumption allows us to model a basic conflict of interest problem in the financial industry that may give rise to the misselling of financial products: should a financial intermediary tell a client that another firm offers a product that better suits the client's needs, or should it try to steer the client to one of its own products? This conflict of interest problem in providing advice to clients has prompted many commentators to advocate the separation of information provision from the sale of financial products. Our results, however, directly challenge the conventional wisdom that information is only credible if it is provided by an independent institution that has no such conflict of interest. Indeed, we find that in various market environments, competition or consolidation (into one-stop banks) can resolve this conflict of interest.

In our basic setup customers do not know which financial product best suits their needs, but financial institutions (who sell some of these products) 
may be able to provide this information to customers. We assume that information is nonverifiable but that financial institutions suffer a reputation costs for misselling. In a heavily regulated environment such as that of financial services, the disclosure of verifiable information can be made compulsory and any attempt to falsify the information can be heavily penalized. However, the issue of inducing revelation of nonverifiable information remains. But, since financial institutions often care about maintaining their relationships with their clients, some discipline in the revelation of nonverifiable information can be imposed through reputation costs for giving misleading advice.

Although our research is primarily motivated by issues relevant to the financial services industry, our findings apply to any market in which buyers are uncertain about which product is best for them and sellers face a reputation cost if they provide misleading information. Examples of such markets outside the finance industry might include the market for medical procedures, the market for real estate, and the market for sophisticated technical equipment.

Our main findings are as follows. Competition among specialized financial intermediaries can lead to full credible information disclosure, even in the presence of only small reputation costs. The basic intuition for this result is that competition both reduces the gains from lying and induces financial institutions to disclose information in order to differentiate their products and, thus, relax price competition. By credibly disclosing information financial institutions can restore their margins on a smaller base of customers 
that have special needs. However, the size of potential reputation costs limits profit margins because with high profit margins the advice provided to clients is no longer credible. As a consequence, sellers could still gain from the presence of a third party (such as an independent financial advisor) that provides information, allowing them to raise margins further.

One-stop banks, defined here as banks that sell multiple products, can also overcome this conflict of interest in certain circumstances. While the creation of one-stop banks is usually motivated by an economies of scope argument, according to which it is more efficient to sell multiple financial products from the same outlet, we find that the increased ability to credibly provide information may be another major motive for consolidation. We find that one-stop banks are able to provide reliable information and charge higher prices than specialized banks when they have market power; otherwise, competition among one-stop banks results in a similar outcome as competition among specialized banks.

The model can be applied to both everyday financial products (e.g., a savings bank recommending CDs rather than mutual funds, or an insurance broker steering customers toward certain automobile or home insurance policies) ${ }^{1}$ and more esoteric ones (the most prominent recent example is insurance broker Marsh and McLennan misleading corporate clients as to which insur-

\footnotetext{
${ }^{1}$ Insurance broker Aon has recently been found to systematically steer customers towards the Chubb insurance company, which secretly rewarded Aon's brokers with bonuses ("Aon Inquiry Suggests Problems In Home and Auto Insurance", by Joseph B. Treaster, New York Times, March 7, 2005).
} 
ance contracts were most suitable but also went as far as rigging the bids of competing insurance companies $)^{2}$. The case of mutual funds is particularly informative. It is commonly accepted that there is much uncertainty on the part of investors when choosing mutual funds (see Sirri and Tufano, 1998; Hortacsu and Syverson, 2004). Firms that provide mutual funds therefore play a critical role in guiding investors. A vast body of evidence suggests that large firms push their own products over alternatives. For example, Charles Schwab, which proclaims in many advertisements its "independence from conflicts of interest so common on Wall Street" was found to have put four of its own funds on its 'short list' of 20 funds (the next highest number of funds from one fund group was two $)^{3}$. Edward Jones recently paid $\$ 75$ million in penalties for "promoting the sale of the Preferred Families' mutual funds because of the funds' long-term investment objectives and performance" while failing to disclose that it received tens of millions of dollars each year from Preferred Families. ${ }^{4}$ While some examples are not as much a problem of matching products with the right consumers as a problem of recommending the best products, we find that regardless of whether we model competition as a matching problem or merely vertical differentiation, we obtain similar predictions. ${ }^{5}$

\footnotetext{
${ }^{2}$ See for example "Risky Business: Insurers Reel From Spitzer's Strike; Subpoena on Bid-Rigging Spurred Rush to Admit Collusion With Broker; Fallout for a Family Dynasty", by Monica Langley and Theo Francis, Wall Street Journal, October 18, 2004.

3 "Schwab Gives Own Funds Top Billing - Brokerage Firm's 'Short List' Includes 4 of Its Portfolios, Raising Concerns of Conflict", by Aaron Lucchetti, Wall Street Journal, September 3, 2002.

${ }^{4}$ From www.sec.gov/news/press/2004-177.htm.

${ }^{5}$ In the body of the paper we analyze a model that involves a matching problem between
} 
The main theoretical novelty of the paper is that firms' actions (the prices they set) define the ensuing signaling game (the advice banks give to customers). These actions commit the firms to credible or noncredible information revelation by providing incentives to tell the truth or not. In most other signaling models, payoffs are determined by current or future actions, not by past actions as in our model. Moreover, in these models, each firm signals its private information as in Mailath (1989), for example. Here, the private information is the information a bank acquires about its customer's financial profile, which the bank can reveal as it wishes.

Our model incorporates several features from the industrial organization literature. Given that all customers are uncertain of which product they prefer, there are elements of both horizontal differentiation (Hotelling, 1929) and vertical differentiation (Shaked and Sutton, 1983). Also our model involves an information revelation game in which talk is not cheap. In contrast, most other models that have been considered in the literature involve agents providing information that is either cheap talk or verifiable. As is well known, when private information is verifiable, voluntary disclosure often leads to full information revelation (see Grossman and Hart, 1980; Milgrom and Roberts, 1986; Okuno-Fujiwara, Postlewaite, and Suzumura, 1990).

The issue of provision of information prior to a sale has been discussed in different settings. For example, Benabou and Laroque (1992) and Morgan

customers and financial services. We discuss a slight modification of this model that involves only vertical differentiation in footnotes 9, 17 and 23. 
and Stocken (2003) discuss a conflict of interest similar to the one we look at in the context of stock recommendations. However, our analysis focuses on direct price competition between information providers, whereas these models consider information providers that benefit from subsequent movements in the secondary market price of a recommended stock.

In some ways, the environment we consider also resembles the literature on credence goods, first discussed in Darby and Karni (1973). For such goods or services the consumer is never able to completely ascertain the quality of the good and must therefore rely on the advice of experts (an example of a credence service is automobile repairs - all one knows is whether the car functions properly, not whether the repair was necessary or well executed). Several papers that discuss credence goods analyze the credible revelation of information (Pitchik and Schotter, 1987; Emons 1997, 2001) and competition among credence good providers (Wolinsky, 1993; Pesendorfer and Wolinsky, 2003). However, in our model, the financial instruments are experience goods, since misleading customers can result in a reputation cost. Moreover, in credence good models, experts can provide the full range of treatments; here, we consider financial intermediaries who may have only one product to offer. ${ }^{6}$

The problem we analyze is also related to the literature on referrals. In a recent contribution Garicano and Santos (2004) discuss efficiency in matching clients with the correct agents when referrals are possible. Since agents may have private information about a client's value, an adverse selection

\footnotetext{
${ }^{6}$ We thank Jennifer Reinganum for this observation.
} 
problem arises. In addition, Garicano and Santos allow for moral hazard in helping clients. We allow for costless referrals, focusing on the potential for price competition to incentivize the revelation of information. In contrast, Garciano and Santos abstract away from competition for customers to focus on the allocation problem. However, Garciano and Santos find that partnerships may provide incentives to allocate clients efficiently, much as we find that one-stop banks have greater incentives to match customers correctly to products, although for different reasons. In Garciano and Santos, partnerships create a moral hazard problem for the referent, weakening incentives to lie about the client.

Finally, Demski and Sappington's (1987) and Shavell's (1994) contributions also relate to information acquisition and disclosure, although in a different setting from ours. In Demski and Sappington (1987) the service provided by the agent is a form of credence good and the agent can only be incentivized to acquire information with an output-based compensation scheme. In contrast, in Shavell (1994), while information is verifiable, it is not observable whether the agent has acquired the information. Thus, to be able to limit information disclosure ex post, the agent has an incentive not to always acquire the information. The largest difference between these papers and our analysis is that we permit Bertrand competition between sellers, while both Shavell (1994) and Demski and Sappington (1987) focus on bilateral buyer-seller contracting relations.

The paper is organized as follows: Section 2 describes the model. Section 
3 studies the benchmark case of monopoly banks. Section 4 considers information production and competition among specialized banks and in Section 5 we study how incentives change in the presence of one-stop banks. In Section 6 we analyze market structure, while in Section 7 we study the case in which bank investment in the production of information is not observable. Section 8 concludes. Finally, a mathematical appendix collects all the proofs of our results and explores the robustness of our analysis to alternative model specifications.

\section{The model}

We consider a model in which two financial intermediaries (FIs) compete by offering one or possibly two different types of financial products, $A$ and $B$. These financial intermediaries could be banks that issue credit cards or business loans to small firms, mutual fund companies selling managed accounts or index funds to individual investors, insurance companies that sell different types of insurance packages to individuals or corporations, or other firms that combine sales and advice to potentially uninformed customers. ${ }^{7}$

\footnotetext{
${ }^{7}$ Another possible application of our model is that of hedging products sold to corporations, where, for example, product $B$ is a "plain vanilla," easily valued, market traded derivative contract, while product $A$ is either a customized swap contract or a more complex derivative contract such as a zero premium collar that is much harder to value for a customer. We thank Douglas Diamond and David Blair for suggesting this interpretation.
} 


\subsection{Customers}

For simplicity, we assume that customers are risk-neutral agents who buy at most one unit of a financial product from an FI.

We assume that customers could be of two different types, $A$ and $B$, reflecting their different investment preferences or profiles. Type- $A$ investors derive a gross payoff of $R$ when they are matched with product $A$ and a gross payoff of $r(r<R)$ when they are matched with product $B$. Similarly, type- $B$ investors realize a payoff of $R$ when they are matched with produce $B$ and a payoff of $r$ when they are mismatched. We denote by $\Delta$ the difference $R-r$.

Customers do not know which of the two products is best suited for their needs. For example, they may be unaware of important tax or liquidity advantages of one of the products or they may not be aware of specific fine print contractual clauses. We model this lack of knowledge as incomplete information about their true type. ${ }^{8}$ Thus, all customers know is the prior probability of being of type- $A$, which is denoted by $q$. In addition, we assume that this prior probability is equal to the true proportion of type- $A$ customers, and that $q>\frac{1}{2}$ (without loss of generality). ${ }^{9}$ Given this information and the

\footnotetext{
${ }^{8}$ Equivalently, we could interpret this lack of knowledge as incomplete information about the type of the financial product that matches each customer's needs.

${ }^{9} \mathrm{We}$ can adapt this basic model to one that emphasizes vertical differentiation by distinguishing between $q$, the customer's prior belief of being type $A$, and $z$, the true proportion of type- $A$ customers. As $z$ approaches one, products $A$ and $B$ become more vertically differentiated, as most customers then favor $A$ over $B$. Generally, our analysis easily adapts to this modified model and most of our qualitative conclusions remain the same. We discuss how results from this adapted model differ from our current one in footnotes 17 and 23 .
} 
prices of the financial products posted by the FIs, customers determine which FI to approach. This choice will depend not only on the product's price but also on whether the FI is expected to provide reliable information on the customers' types. For example, should a customer approaching FI $A$ obtain information that FI $B$ offers the best deal (a better-matched product at competitive terms), she will switch to FI $B$. In our basic model, we assume that an FI's investment in information provision technology is observable. We abandon this assumption in Section 7. We also assume that the switching cost technology is such that a customer may switch between banks only once. ${ }^{10,11}$

\subsection{Financial intermediaries}

We consider two types of FIs, specialized FIs and "one-stop banks." A specialized FI is one that offers only one financial product, whereas a one-stop bank offers both types of financial product. ${ }^{12}$

For most of our analysis the cost of production for the two products is

\footnotetext{
${ }^{10}$ Pesendorfer and Wolinsky (2003) consider situations in which uninformed customers may seek second opinions. In their model, however, sellers can only communicate noisy information to their customers.

${ }^{11}$ In the U.S., the average number of banks with which small businesses have relationships is 1.5 ( $60 \%$ of businesses only have relationships with 1 bank, $26 \%$ with two banks) which indicates that businesses tend to minimize their number of relationships. If we extend this by adding all financial institutions, the average number is 2 ( $42 \%$ of businesses only have relationships with one bank or institution, $28 \%$ with two). These data are taken from the National Survey of Small Business Finances (NSSBF), 1998.

${ }^{12}$ The terms universal bank or financial conglomerate are also commonly used to describe a one-stop bank. Here, we prefer the term one-stop bank since the first term carries a connotation of economies of scope and the second a connotation of regulatory arbitrage, which are both absent from our framework.
} 
the same and is normalized to zero. This means that the prices of the two products, $p_{A}$ and $p_{B}$, are interpreted as spreads.

Although customers do not know their type, FIs may know which product best fits the needs of each customer. FIs can offer an advisory service and guide customers to the relevant product but they may face a conflict of interest problem in their dual role as financial advisors and sellers of financial products. This conflict of interest may put them in a position in which they may not be able to credibly communicate to customers their information about a good match since they have an incentive to peddle their own product. Customers understand this and will only follow an FI's recommendation if it is in the FI's interest to truthfully reveal its information.

An FI's incentive is driven in part by a desire to maintain a reputation for honest advice and in part by competitive pressure, which limits the FI's ability to benefit from its provision of information. To model the reputational concern we assume that an FI suffers a reputation loss of $\rho$ when a lie told to a customer leads to a purchase by that customer. This loss arises because the financial product is an experience good; the customer realizes a return from her investment and can compare that with the initial expected return promised her by the FI. We interpret the reputation cost as a loss of future business from that customer or from word-of-mouth that the bank is providing deliberately misleading or confusing advice. In the Appendix (Section 10.6) we verify the robustness of the model to a more general definition 
of reputation, ${ }^{13}$ and we also find similar results to those of the text when the reputation cost is endogenized. ${ }^{14}$

Obviously, if this reputational loss is very large then the incentive for FIs' to peddle their products disappears. We formalize this observation in the following assumption.

Assumption A1: $\operatorname{Min}(\Delta, r)>\rho$.

This assumption allows us to focus on the more relevant case where a conflict of interest arises. If $\rho$ is too large, then there is no choice but to reveal full information since the firm will be strictly punished for not doing so. Although we place an upper bound on $\rho$, we allow $\rho$ to be as low as zero, in which case the analysis reduces to a pure cheap talk game.

We restrict customers' strategies with the following assumption.

Assumption A2: There is a tiny amount of uncertainty on the part of firms about the actual values of $\rho$ and $R$, i.e. $\rho \in\left[\tilde{\rho}-\varepsilon_{1}, \tilde{\rho}+\varepsilon_{1}\right]$ and $R \in\left[\tilde{R}-\varepsilon_{2}, \tilde{R}+\varepsilon_{2}\right]$ such that $\varepsilon_{1}, \varepsilon_{2} \rightarrow 0$.

For any small amount of uncertainty, however small, firms are unable to

\footnotetext{
${ }^{13}$ In this more general definition, we allow for two reputation costs. One reputation cost is incurred when the FI lies and misleads the customer into purchasing the wrong product and the other reputation cost is incurred when the FI lies but doesn't mislead the customer. This analysis is less tractable (partially revealing equilibria are not trivial) but yields essentially the same equilibrium as the model we analyze.

${ }^{14}$ Specifically, if the reputation cost takes the form $\bar{\rho}+\theta \pi$, where $\bar{\rho}$ is an exogenous fixed cost and $\theta \pi$ is an endogenous cost that varies with current profits (with $\theta<1$ ), the model maintains exactly the same structure and results (instead of a cutoff of $\rho$ for information regimes, the cutoff is $\left.\frac{\bar{\rho}}{1-\theta}\right)$. It is important that some part of the reputation cost be exogenous. One possible interpretation of this exogenous component is that it represents a loss in profits on other unrelated financial products (such as deposits) or businesses run by the bank. Another possibility is that it represents a part of future demand growth. Lastly, it might represent a legal penalty.
} 
set prices at the exact levels necessary to make consumers indifferent between choices (or to balance the reputation effect). Thus, this small uncertainty limits customers to pure strategies and eliminates multiple equilibria.

\subsection{Timing}

1. FIs decide whether to invest in information provision technology.

2. FIs set prices. To simplify the strategic analysis we will give one of the FIs a price leadership role (that is, one of the FIs moves first in setting prices). ${ }^{15}$

3. Investors approach an FI, who then recommends a financial product.

4. Investors make a decision regarding which product to purchase from which FI, based on observed prices and the FI's recommendation. ${ }^{16}$

We begin with a brief analysis of monopoly banking.

\footnotetext{
${ }^{15}$ This assumption allows us to rule out mixed strategy equilibria that would naturally arise if FIs were setting prices simultaneously (see footnote 19).

${ }^{16}$ In a slightly richer setting one might want to allow customers to seek advice from more than one FI. All the equilibria with full truthful information disclosure that we characterize here would still obtain in this richer setting, as there is no point for customers to seek a second opinion in these equilibria. However, other equilibria might obtain in the richer setting. Whether there is more information disclosure in this richer setting is unclear. Indeed, if a reputation cost is incurred by any FI that provides information whenever a customer receives a different recommendation, then both more misselling and more truthtelling is likely.
} 


\section{Monopoly banking}

\subsection{A specialized monopoly}

Under no information provision, a specialized monopoly FI sets the monopoly spread at either $r+q \Delta$ for an $A$ bank, or $r+(1-q) \Delta$ for a $B$ bank. Under full information a specialized bank either serves all customers at a maximum spread of $r$ or it only serves well-matched customers at a monopoly spread of $R$. Thus, an $A$ monopoly bank's payoff under full disclosure is $\max \{r, q R\}$ and a $B$ bank's payoff is $\max \{r,(1-q) R\}$. Since $r+q \Delta>\max \{r, q R\}$ for an $A$ bank and $r+(1-q) \Delta>\max \{r,(1-q) R\}$ for a $B$ bank, it appears that both specialized FI monopolies always prefer uniformed consumers as long as reputation costs for steering customers to the wrong product are sufficiently low. Indeed, analyzing the pricing decision and the signaling game when the FI can decide to provide information (i.e., where customers must purchase product $i=A, B$ or receive their reservation utility of zero, and the FI can say whether product $i$ is a good or bad match), we confirm the following result in the Appendix:

Proposition 1 Under assumptions $A 1$ and A2, a monopoly FI A reveals no information (always recommends product $A$ ) and sets price $p_{A}=r+q \Delta$. A monopoly FI B reveals no information (always recommends product B) if $\rho<\frac{1-q}{q} \Delta$ and sets price $p_{B}=r+(1-q) \Delta$. If $\rho>\frac{1-q}{q} \Delta$, FI B sets $p_{B}=r$ and fully reveals its information. 
Under our assumptions, the rents from selling to all of the market always outweigh the reputation cost of lying to a fraction of the customers for FI $A$, and for low enough reputation costs $\rho$ also for FI $B$. The difference between the two FIs is due to the fact that FI $B$ incurs a higher expected reputation cost of lying and realizes a smaller financial return, since the proportion of customers that are well matched with product $A$ is higher. As simple as this observation maybe, it nevertheless highlights the important general principle that the more advantaged FIs, i.e., those that a priori are selling the better product, are most likely to lie to their customers. ${ }^{17}$

\subsection{Monopoly pricing of a one-stop bank}

The key difference between a specialized and a one-stop FI in our model is that the latter can more easily overcome the conflict of interest problem in the provision of information. The reason is that information provision need no longer result in any loss of clientele. This is an important potential benefit of one-stop banks, and is emphasized by bankers who deal with the marketing of financial products.

More formally, assume now that a one-stop bank, which we refer to as FI 1 , offers both financial products $A$ and $B$ at prices $p_{1 A}$ and $p_{1 B}$. Under no information provision, the best FI 1 can do is to only sell product $A$

\footnotetext{
${ }^{17}$ If the products were vertically differentiated, FI $B$ would have even larger incentives to fully reveal information to avoid the large reputation cost from lying. FI $B$ would only not reveal information if $\rho<\frac{1-q}{z} \Delta$, where fraction $z$ of the population actually prefers product $A$ (and $z$ approaches one).
} 
at price $p_{1 A}=r+q \Delta$. Its actions emulate those of a specialized bank. When FI 1 can provide information, it can do substantially better by setting $p_{1 A}=p_{1 B}=R$, segmenting the market, and extracting full rents through the truthful provision of advice.

Proposition 2 A monopoly one-stop bank fully reveals information, customers purchase the product that matches their type, and prices are $p_{1 A}=$ $p_{1 B}=R$.

The proof is in the Appendix. Note that when $\rho>0$, the one-stop bank can credibly reveal the information it has about customer types. The reason is simply that by setting the same prices for the two products, it eliminates the incentive to misdirect the customer, and saves the reputation cost $\rho$ when it tells the truth. Moreover, by telling the truth, the one-stop bank can increase customers' valuations for the products. It can then set prices equal to $R$, tell the truth, and simultaneously extract all rents. When $\rho=0$ the bank is indifferent and truth-telling is not a unique equilibrium.

This section highlights a simple but important economic principle, namely monopoly one-stop banks are better able to overcome the conflict of interest problem in advising their clients on what product is best for them. We shall see in the next section, however, that when there is competition among banks this general principle is no longer valid. Put simply, competition induces information revelation whether it is between specialized banks or between one-stop banks. ${ }^{18}$

\footnotetext{
${ }^{18}$ We take the reputation cost per customer incurred when lying as exogenously fixed
} 


\section{Competition among specialized FIs}

This section determines under what conditions, if any, a specialized FI has incentives to provide information to its customers in a competitive (BertrandNash) equilibrium. As we have already pointed out, specialized FIs have a conflict of interest in advising their prospective customers to bank at a competitor FI. At the same time, truthful revelation increases the customers' valuations for the bank's products. These opposing incentives determine the equilibrium amount of revelation. Before analyzing the FIs' incentives for truthful revelation it is helpful to first consider the extreme situations of no information revelation and full information disclosure.

\subsection{Competition with no information}

In the absence of any additional information, a customer buys product $A$ from the FI who specializes in $A$ if and only if

$$
q R+(1-q) r-p_{A} \geq q r+(1-q) R-p_{B}
$$

That is, if and only if

$$
(2 q-1) \Delta \geq p_{A}-p_{B}
$$

at $\rho$. It might be argued, however, that the reputation cost varies with market structure. To the extent that monopolists extract larger mark-ups they may be more wary of losing future customers. On the other hand, monopolists face a captive demand, which makes them less concerned about losing business to competitors. How these countervailing effects play out requires a more detailed analysis, which is beyond the scope of this paper. 
Thus, FI $A$ sets price $p_{A}=(2 q-1) \Delta$, forcing FI $B$ to zero profits. ${ }^{19}$ For this price level the customer's participation constraint is satisfied, i.e.,

$$
q R+(1-q) r-(2 q-1) \Delta=R-q \Delta \geq 0 .
$$

As is intuitive, the larger the product differentiation $\Delta$ and the larger the probability that customers are of type- $A$, the larger the price difference and $A^{\prime}$ s profits. The closer $\Delta$ is to zero and/or the closer $q$ is to $\frac{1}{2}$, the more intense the competition between the FIs and the larger is the customer's surplus, as the two products become close substitutes from the perspective of uninformed customers. Absent any information, FI $B$ makes zero profits due to the ex ante preference of customers for product $A$.

\subsection{Competition under full information}

Suppose that a customer knows her true type. All type- $A$ customers are then likely to bank at FI $A$, and all type- $B$ customers to bank at FI $B$. In other words, each FI is likely to have a captive clientele. This will have the effect of dampening price competition as each FI will be reluctant to cut prices low enough to attract mismatched customers. This idea is formulated in the following proposition.

\footnotetext{
${ }^{19}$ That is, assuming that FI $A$ is the price leader. If FI $B$ is the price leader, there is a continuum of equilibria, each with a different $p_{B}$ that is 'undercut' by FI $A$ with a best response $p_{A}=\min \left[(2 q-1) \Delta+p_{B}, q R+(1-q) r\right]$ (since FI $B$ always makes zero profits it does not care which $p_{B}$ it sets). Note that this set contains the equilibrium in which FI $A$ is the price leader.
} 
Proposition 3 Under full information, if FI A is the price leader, the equilibrium prices are

i) If $q R<2 \Delta, p_{A}=\min [(1-q) R+\Delta, R], p_{B}=R$, and profits are $\pi_{A}=q p_{A}$ and $\pi_{B}=(1-q) R$, and

ii) if $q R>2 \Delta, p_{A}=\frac{2-q}{q} \Delta, p_{B}=\frac{2}{q} \Delta$, and profits are $\pi_{A}=(2-q) \Delta$ and $\pi_{B}=\frac{2(1-q)}{q} \Delta$.

This is proven in the Appendix. Note that if FI $B$ becomes the price leader, the results are symmetric (switch $A$ for $B$ and $q$ for $1-q$ ).

The comparison of this result with the no information case highlights the mitigating effect of quality uncertainty (Bester, 1998). Information production increases efficiency (total surplus here is $R$, compared to $q R+(1-q) r$ in the no information case), but it also decreases the potential for competitive prices as every firm has market power over its own type. We show in the next subsection that this monopoly power is impaired, however, by the FIs' conflict of interest problem in advising its customers.

\subsection{Competition under credible information production}

When FIs must be induced to give honest advice they are less in a position to exploit their local monopoly power. The reason is simply that if they charge high prices and also recommend their highly profitable product to prospective customers this recommendation is not credible. 


\subsubsection{The information revelation game for a specialized FI}

Once FIs have set their prices and customers have made their decision regarding which FI to approach, an FI that has invested in information provision can ascertain the customer's true types. We analyze the incentives of this FI to truthfully provide information in a signaling game in which the FI's type is its information about the customer.

An FI's strategy can be summarized by two variables: the probability $\alpha$ that a type- $A$ customer is correctly advised to choose product $A$ and the probability $\beta$ that a type- $B$ customer is wrongly advised to select product A.

Having received a recommendation $\widehat{A}$ to purchase product $A$, or $\widehat{B}$ to purchase product $B$, a customer's strategy can be described, symmetrically, by the probability $a$ of following the advice to take product $A$, and the probability $b$ of following the advice to take product $B$. Fig. 1 shows the basic information revelation game structure.

We begin by characterizing Perfect Bayesian Equilibria in the information revelation game of FI $A$, taking as given the prices quoted by the FIs and the customers' decisions as to which FI to approach. In a second step, we move back in the game tree and solve for the equilibrium prices and customer decisions on where to bank in the full game. In a Perfect Bayesian Equilibrium, each agent optimally chooses its strategy given equilibrium (and out-ofequilibrium) beliefs and the other agents' strategies. For out-of-equilibrium beliefs we rely on the Cho-Kreps (1987) intuitive criterion to pin down beliefs. 


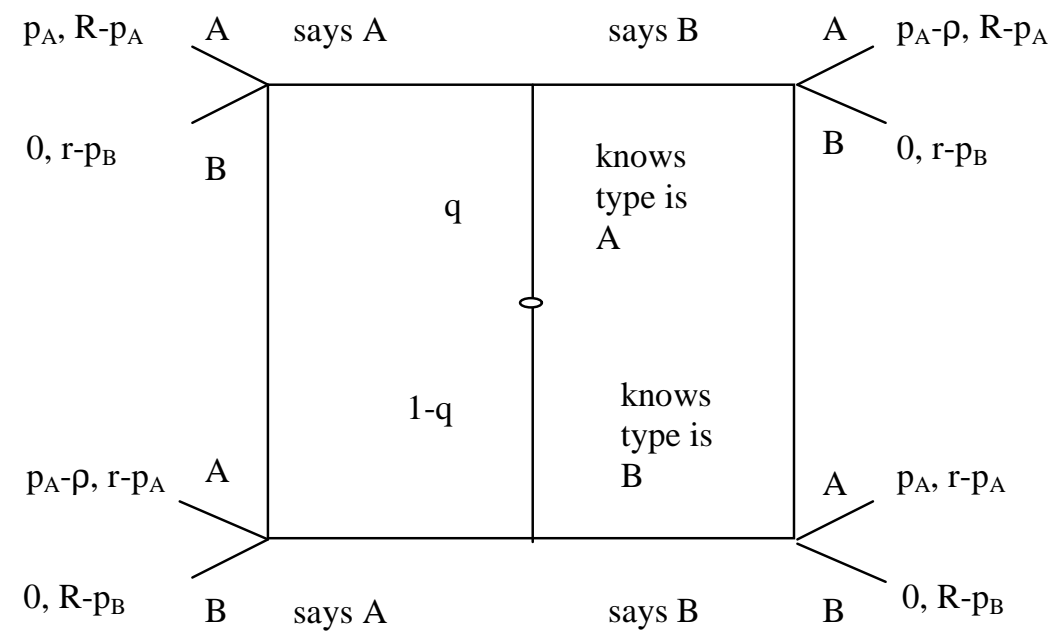

Fig. 1. The information revelation game.

FIs maximize their profits net of the reputation cost of lying. Thus, when FI $A$ observes a type- $A$ customer, the necessary condition for FI $A$ to truthfully reveal $A$ 's type is

$$
a p_{A} \geq(1-b)\left(p_{A}-\rho\right),
$$

or equivalently,

$$
\Delta \pi_{A}(A) \equiv(a+b-1) p_{A}+(1-b) \rho \geq 0 .
$$

Symmetrically, when FI $A$ observes a type- $B$ customer, the necessary 
condition for FI $A$ to truthfully reveal $B$ 's type is

$$
\Delta \pi_{A}(B) \equiv-(a+b-1) p_{A}+a \rho \geq 0 .
$$

In general, FIs may play mixed strategies.

When customers receive a recommendation, they use equilibrium-updated beliefs to compute their optimal strategies. Under assumption A2, however, customers only use pure strategies. Denote by $\widehat{X}$ the announcement a customer receives and by $p(i \mid \widehat{X})$ the updated belief that a customer receiving the announcement $\widehat{X}$ is of type $i$, where $i=A, B$ and $\widehat{X}=\widehat{A}, \widehat{B}$. The necessary condition for a customer receiving a recommendation $\widehat{A}$ at FI $A$ to buy product $A$ is then

$$
p(A \mid \widehat{A}) R+(1-p(A \mid \widehat{A})) r-p_{A} \geq p(A \mid \widehat{A}) r+(1-p(A \mid \widehat{A})) R-p_{B}
$$

This can be simplified to

$$
(2 p(A \mid \widehat{A})-1) \Delta \geq p_{A}-p_{B}
$$

or equivalently,

$$
\Delta U_{A}(\widehat{A}) \equiv(2 p(A \mid \widehat{A})-1) \Delta-p_{A}+p_{B} \geq 0 .
$$

Similarly, the necessary condition for a customer receiving a recommen- 
dation $\widehat{B}$ at FI $A$ to buy product $B$ is

$$
\Delta U_{A}(\widehat{B})=(2 p(B \mid \widehat{B})-1) \Delta-p_{B}+p_{A} \geq 0
$$

A Perfect Bayesian Equilibrium is then defined by a set of posterior beliefs $p(i \mid \widehat{X})$, which are consistent with the optimal behavior of FIs and customers as inferred from the signs of $\Delta \pi_{A}(A), \Delta \pi_{A}(B), \Delta U_{A}(\widehat{A})$, and $\Delta U_{A}(\widehat{B})$. The following lemma provides a characterization of the FIs' information revelation in equilibrium and is the central result of our analysis.

Lemma 4 Under assumptions A1 and A2, equilibria in the information revelation game of FI A are as follows:

1. If $p_{A}<p_{B}-\Delta$, then FI A truthfully reveals the customer's type and all customers purchase $A$.

2. If $p_{B}-\Delta<p_{A}<\rho$, then FI A truthfully reveals the customer's type and customers purchase the good that matches their type.

3. If $\max \left[\rho, p_{B}-\Delta\right]<p_{A}<p_{B}+(2 q-1) \Delta$, then FI $A$ always announces $\hat{A}$ and customers purchase $A$.

4. If $p_{A}>p_{B}+(2 q-1) \Delta$, then

(a) FI A mixes its messages for both types of customers $(\alpha, \beta \in(0,1) \times$ $(0,1))$, or mixes its messages for one type of customer $(\alpha=1, \beta \in$ 
$(0,1))$ or $(\beta=1, \alpha \in(0,1))$ within a range defined by

$p_{A}>p_{B}+\Delta \max \left[2 \frac{\alpha q}{\alpha q+\beta(1-q)}-1,1-2 \frac{(1-\beta)(1-q)}{(1-\alpha) q+(1-\beta)(1-q)}\right]$

or

(b) FI A systematically announces $\widehat{A}$ provided the out-of-equilibrium beliefs $P(B \mid \widehat{B})$ satisfy

$$
p_{A}>p_{B}+\Delta \max [2 q-1,1-2 P(B \mid \widehat{B})],
$$

or

(c) FI A systematically announces $\widehat{B}$ provided the out-of-equilibrium beliefs $P(A \mid \widehat{A})$ satisfy

$$
p_{A}>p_{B}+\Delta \max [2 q-1,2 P(A \mid \widehat{A})-1]
$$

and all customers purchase $B$.

5. If $p_{A}>p_{B}+\Delta$, then all customers purchase $B$ and any revelation strategy (including full revelation) is an equilibrium.

The proof of the lemma is in the Appendix. We can now use it to determine for a given set of parameters $\rho, q, \Delta$ and prices $p_{A}$ and $p_{B}$, in which information revelation regime a firm is located. In one interval, 
$p_{B}+(2 q-1) \Delta<p_{A}<\rho$, there exist multiple equilibria: a fully revealing equilibrium in which customers follow FI $A$ 's advice, and many partially revealing equilibria in which all customers purchase product $B$. However, given that $p_{A}<\rho$, any partially revealing strategy by a FI $A$ type is weakly dominated by a strategy of full revelation. Hence, the partially revealing strategy will not survive any tiny trembles in the customer's decision, and thus we ignore it. ${ }^{20}$

Since FI $A$ and FI $B$ are symmetric except for a consumer's ex ante preferences, we can replicate Lemma 2 for FI $B$ by substituting $(1-q)$ for $q$.

In Fig. 2 we fix $p_{B}$ and display FI $A$ 's information revelation regime for any possible $p_{A}$ that it may set. We find that when FI $A$ sets very low prices, it is induced to reveal information truthfully and can capture the whole market. In contrast, when FI $A$ sets high prices, it will not attract any customers, and will be willing to say anything. For a middle range of prices, FI $A$ may credibly reveal information and only capture those customers who are good matches, or it may reveal nothing and take advantage of its ex ante advantage in terms of consumers' preferences.

At this point we have solved the subgame of information revelation given fixed prices. We can now determine how each firm sets its prices and then

\footnotetext{
${ }^{20}$ More formally, type "Knows customer is type $A$ " obtains a payoff of either 0 or $p_{A}$ by announcing $\hat{A}$ and obtains a payoff of either 0 or $p_{A}-\rho$ by announcing $\hat{B}$. In the interval of parameters under consideration we have $p_{A}<\rho$, so weak dominance is clear. Similarly, type "Knows customer is type $B$ " obtains a payoff of either 0 or $p_{A}$ by announcing $\hat{B}$ and obtains a payoff of either 0 or $p_{A}-\rho$ by announcing $\hat{A}$. Therefore, any partially revealing equilibrium in this interval does not survive the test of trembling hand perfection.
} 


$$
\begin{aligned}
& 0 \leq \rho<p_{B}-\Delta \\
& \begin{array}{lccll}
\hline \begin{array}{l}
\text { Fully } \\
\begin{array}{l}
\text { Revealing, all } \\
\text { buy A }
\end{array}
\end{array} & p_{B}-\Delta & \begin{array}{l}
\text { Not Revealing } \\
\text { in A, all buy A }
\end{array} & p_{B}+(2 q-1) \Delta & \begin{array}{l}
\text { Partially } \\
\text { Revealing, all } \\
\text { buy B }
\end{array}
\end{array} \\
& p_{B}-\Delta \leq \rho<p_{B}+(2 q-1) \Delta
\end{aligned}
$$

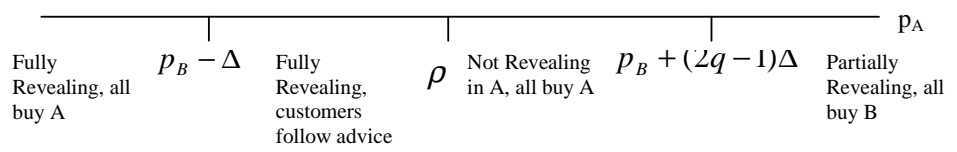

$$
\begin{aligned}
& p_{B}+(2 q-1) \Delta \leq \rho
\end{aligned}
$$

\begin{tabular}{lcll|l}
\hline Fully & & & Pulty \\
$\begin{array}{l}\text { Revealing, all } \\
\text { buy A }\end{array} \quad p_{B}-\Delta$ & $\begin{array}{l}\text { Fully } \\
\text { Revealing, } \\
\text { customers } \\
\text { follow advice }\end{array}$ & $\rho$ & $\begin{array}{l}\text { Revealing, all } \\
\text { buy B }\end{array}$ \\
\hline A
\end{tabular}

Fig. 2. The information revelation regimes of FI $A$ (holding $p_{B}$ fixed).

determine which firm invests in information provision in equilibrium.

\subsubsection{The price competition game between specialized FIs}

The previous lemma characterizes a number of scenarios in which there is either partial or no credible information disclosure, given $p_{A}$ and $p_{B}$. These limited information disclosure outcomes are what one would expect to see in light of our observation that specialized monopoly FIs are never able to credibly convey information. We now show, however, that price competition among specialized FIs is likely to bring about equilibrium outcomes such that each FI credibly conveys information. To see this, suppose for the sake of argument that specialized FIs are never able to credibly convey information. 
Then, as we showed earlier, Bertrand competition under no information will result in an equilibrium outcome where $\pi_{B}=0$ and $\pi_{A}=(2 q-1) \Delta$. Note, however, that bank $B$ will then have a strict incentive to truthfully reveal the customer's type as long as $\rho>0$. This is due to the fact that bank $B$ would be able to raise its price $p_{B}$ up to $\rho$, credibly convey information to its well-matched customers, and make higher profits.

In our formal analysis of the price competition stage game we assume that firm $A$ is the price leader and firm $B$ is the price follower (when instead FI $B$ is the price leader, the qualitative results do not change substantially, as we show in the Appendix). This means that FI $A$ essentially defines the choice set of possible information revelation regimes (with their accompanying profits) and FI $B$ decides where to locate within the choice set. Our simple observation above then leads us to the following conclusion, as formalized in Proposition 5.

Proposition $5: 1)$ When $A$ invests in information and $B$ does not, there are two possible equilibria. If $\rho>(2 q-1) \Delta$, the equilibrium is $p_{A}=\rho$ and $p_{B}=\rho+\Delta$. All customers approach FI A, and FI A reveals their true types. Customers then purchase at the bank that matches their type, so profits are $\pi_{A}=q \rho$ and $\pi_{B}=(1-q)(\rho+\Delta)$. If $\rho<(2 q-1) \Delta$, the equilibrium is $p_{A}=(2 q-1) \Delta$ with $p_{B}$ undetermined. All customers approach FI A, are all told they are type- $A$, and purchase at FI A. Profits are $\pi_{A}=(2 q-1) \Delta$ and $\pi_{B}=0$.

2) When $B$ invests in information and $A$ does not, the equilibrium is 
$p_{A}=\min [(1-q) \rho+\Delta, \rho+(2 q-1) \Delta], p_{B}=\rho$, all customers approach FI B, and FI B reveals their true types. Customers follow the advice of FI B and profits are $\pi_{A}=q p_{A}$ and $\pi_{B}=(1-q) \rho$.

3) When both $A$ and $B$ invest in information, the equilibrium is $p_{A}=$ $\min [(1-q) \rho+\Delta, \rho+(2 q-1) \Delta]$ and $p_{B}=\rho$, just as in the case of only $B$ investing in information. All customers approach FI B or are indifferent between approaching FI A or FI B, and they are all told their true types. Customers follow the advice of the bank they approach and profits are $\pi_{A}=$ $q p_{A}$ and $\pi_{B}=(1-q) \rho$.

The proof is in the Appendix. For almost all of the cases, complete information revelation occurs in equilibrium and prices are such that customers purchase the product that matches their type. The only case in which information is not revealed occurs when only FI $A$ invests in information provision and ex ante valuations are so biased towards product $A((2 q-1) \Delta>\rho)$ that FI $A$ can extract higher rents by not revealing information. We show in the next subsection, however, that in this latter case only FI $B$ would invest in information ex ante, if any FI invests at all, and only FI $B$ would fully reveal its information ex post.

\subsubsection{The information provision game between specialized FIs}

We are now able to roll back to the first stage of the game, where FIs make their investment in information provision decisions. So far we have taken the information structure, i.e., which bank provides information, as 
given. Now we let banks choose whether they want to invest in an information provision technology (hire analysts, build IT systems, etc.) at some fixed $^{21}$ cost $f>0$. To the extent that information provision is a public good and is costly to produce it is efficient for at most one bank to provide this information. We now show that in equilibrium no more than one bank will provide information, and that it is the disadvantaged bank (i.e., FI $B$ ) that is likely to provide that information. This follows from the fact that the disadvantaged bank is the one with the strongest incentives to truthfully reveal information. Consequently, we are able to obtain the remarkable result that, as long as investment in information provision is profitable in equilibrium, there will always be full information disclosure under competition between specialized FIs.

The basic logic that leads us to this conclusion is as follows. Under no information provision, the unique equilibrium (in profits) is such that $\pi_{B}=0$ and $\pi_{A}=(2 q-1) \Delta$. If bank $A$ were to provide information and communicate it credibly to its customers, it would have to set its margin $p_{A}$ no higher than $\rho$. Thus, bank $A$ 's profits under full credible information revelation would be no more than $q \rho-f$. Therefore, bank $A$ would not want to provide information whenever $(2 q-1) \Delta \geq q \rho-f$. Proposition 5 also states that, when $(2 q-1) \Delta \geq \rho$ and only bank $A$ is in a position to provide information,

\footnotetext{
${ }^{21}$ If we assumed instead that there was a constant marginal cost per customer, the results would be qualitatively the same. Examining a game in which the FIs only inform a fraction of their customers (i.e., if they randomize or have a convex cost function) is outside the scope of this paper.
} 
there will be no credible information disclosure in equilibrium. This appears to set a limit on the amount of credible information disclosure we should expect to see in an equilibrium with competition between specialized FIs.

However, since bank $B$ has, if anything, even more to gain from providing information, there will be full credible information disclosure in equilibrium for a much larger set of parameter values.

Proposition 6 There is full credible information disclosure in pure strategy equilibria when $\rho \geq \frac{f}{1-q}$.

i) For $\rho$ small, i.e., $\frac{f}{1-q}<\rho<\frac{(2 q-1) \Delta+f}{q}$, there is a unique equilibrium in which FI B provides information and FI A does not.

ii) For $\rho$ large, i.e., $\rho>\frac{(2 q-1) \Delta+f}{q}$, three equilibria coexist, one in which only FI A provides information, one in which only FI B provides information; and a mixed strategy equilibrium.

iii) For $\rho<\frac{f}{1-q}$, no information will be disclosed.

The decision to invest is derived from a two-by-two game summarized by the following matrix: ${ }^{22}$

In Fig. 3, we see that FI $B$ has a strong incentive to provide information since the information gives it the market power it was lacking when all customers ex-ante preferred product $A$. FI $A$ can free ride on this information provision as its own investment in information would not change its returns.

\footnotetext{
${ }^{22}$ We take as an upper bound $f<(1-q) \Delta$. This is a necessary condition for FI B to realize positive profits.
} 


\section{FI B}

\begin{tabular}{|c|c|c|c|}
\hline \multirow{4}{*}{ FI A } & & No Info & Info \\
\hline & No Info & $(2 q-1) \Delta, 0$ & $q p_{A^{\prime}}(1-q) \rho-f$ \\
\hline & Info if $\rho>(2 q-1) \Delta$ & $q \rho-f,(1-q)(\rho+\Delta)$ & $q p_{A}-f,(1-q) \rho-f$ \\
\hline & Info if $\rho<(2 q-1) \Delta$ & $(2 q-1) \Delta-(1-q) \rho-f, 0$ & $q p_{A}-f,(1-q) \rho-f$ \\
\hline
\end{tabular}

Fig. 3. Matrix for competition among specialized banks ( $\mathrm{A}$ is the price leader).

In fact, for intermediate values of $\rho$, FI $A$ has a dominant strategy not to provide information since if FI $B$ doesn't provide information FI $A$ can still enjoy its inherent advantage. Once $\rho$ gets larger, FI $A$ can possibly provide information credibly, because it receives a high enough rent to justify its provision. Lastly, notice that as $\rho$ approaches zero, all of FI $B$ 's rents disappear in every scenario. The lack of a reputation cost eliminates the ability to credibly reveal information, which FI $B$ used to achieve positive profits. $^{23}$

Total welfare is maximized in the equilibria in which full information is provided, since each customer is able to realize more utility due to the correct matching. When information is not provided, as is the case when $\rho$ is tiny, matching efficiency is not realized and welfare decreases.

\footnotetext{
${ }^{23}$ In the case of vertical differentiation, FI $B$ 's rents are uniformly lower when information is revealed $((1-z) \rho-f)$, implying that there will be no information revelation for a larger range of $\rho$.
} 


\section{Competition between a one-stop bank and a specialized FI}

We now consider briefly competition between a one-stop bank, FI 1, and another FI that remains specialized and offers, say, product $B$. Since both banks now offer product $B$, competition is more robust in a certain sense. We only discuss the case where FI 1 is the price leader in the body of the text. The case in which FI $B$ is the price leader is covered in the Appendix.

When neither FI provides any information, zero profits are made on product $B$ in equilibrium. Equilibrium profits are then the same as under competition between specialized FIs. Similarly, the equilibrium under full information (i.e., customers know their type) is also identical to that of competition between specialized FIs because, since $B$ plays last, it will undercut FI 1. Hence, the power of FI 1 to set a lower price for product $B$ confers no additional advantage: the one-stop bank does not profit strategically or directly from having product $B$.

When FI $B$ can provide information to customers, however, FI 1 can set the price $p_{1 B}$ strategically to force FI $B$ into an information revelation regime that is favorable to FI 1. This is the main difference between competition between specialized FIs $A$ and $B$, and competition between a one-stop bank FI 1 and a specialized FI $B$. Thus, FI 1's profit here is at least as high, if not higher, than the profits of FI $A$ in the case of competition between 
specialized banks. ${ }^{24}$ Recall that in Section 4.3.3, we find that $p_{A}=\min [(1-$ q) $\rho+\Delta, \rho+(2 q-1) \Delta]$ in the equilibrium in which FI $B$ provides information. In this equilibrium FI $A$ has to set $p_{A}$ sufficiently low to make sure that FI $B$ would not have an incentive to grab the whole market. Now, the one-stop bank can discipline FI $B$ by setting its price for product $B$ sufficiently low to eliminate this incentive, and it is free to set $p_{1 A}=(1-q) \rho+\Delta$. Hence, FI 1 is able to generate higher profits $\pi_{1}=q((1-q) \rho+\Delta)$ in this case. In the cases in which FI $B$ does not provide information, however, FI $B$ can undercut FI $A$ on product $B$, rendering the solutions exactly the same as those when specialized FIs compete.

\section{Market structure}

We are now able to explore the incentives for a specialized bank to expand its activities and become a one-stop bank, and to analyze the welfare implications of such a move. The conditions under which one-stop banks can prosper are quite interesting given current trends. The abolition of the Glass-Steagall act in 1999 paved the way in the United States for the creation of one-stop banks. In Europe, while such banks, called "universal banks," have existed for many years, they are now undergoing a shake-up as mergers across borders are seen as necessary for survival. ${ }^{25}$ The traditional expla-

\footnotetext{
${ }^{24}$ As summarized in the first payoff matrix of Section 4.3.3.

${ }^{25}$ This is echoed in Banking surveys by The Economist (April 4, 2002) and The Financial Times (May 24, 2002).
} 
nation for the trend towards consolidation relates to economies of scope in selling multiple financial products from the same outlet. However, by analyzing these banks from an information provision perspective, we open up a richer understanding of market structure. ${ }^{26}$

\subsection{Trends toward consolidation}

Our analysis points out that the gains from a merger are largest when reputation costs are very low. For very small reputation costs, no information is provided when specialized banks compete, as incentives for misselling are too strong. However, when the market is dominated by a one-stop bank, advice can be credibly provided even if the bank extracts most of the customers' value of information. For higher reputation costs this comparative advantage of one-stop banks is eroded, as specialized banks are also able to give advice credibly.

A specialized bank that is competing against another specialized bank may decide that instead of trying to merge with its competitor, it could extend its product line. Clearly, this would soften competition if the market is already homogeneous (such as competition between two FI Bs). However, another product can also be used as a strategic buffer, keeping the other firm from entering a disadvantageous information revelation regime and therefore allowing for more profits (we see this when the reputation cost is low

\footnotetext{
${ }^{26}$ We also note that the traditional use of the term "conflict of interest" in the context of one-stop banks refers to the underwriting of securities to subsidize bad loans; we do not consider this issue, focusing instead on information provision.
} 
$\left(\rho<\frac{2(1-q)}{q} \Delta\right)$ in competition between FI 1 and FI $\left.B\right)$. Finally, a monopoly specialized bank would gain substantially by turning itself into a multiproduct bank, since this would allow it to raise spreads even more while resolving the fundamental conflict of interest problem it faces in giving advice.

From a welfare perspective, when customers are ex ante fully informed, welfare is maximized under a one-stop bank, although at the expense of consumer surplus. When customers are uninformed, welfare is low as all $B$ types purchase product $A .^{27}$

\subsection{Limits to consolidation}

One important simplifying assumption in our analysis is that the costs of producing each product are known by customers to be the same and normalized to zero. Suppose, however, that the cost of producing product $A$ is substantially lower than that of product $B, c_{A}<c_{B}$. In this case, at equal prices, $p_{1 A}=p_{1 B}$, the one-stop bank stands to make a larger margin on product $A$. The one-stop bank may then have a strong incentive to steer customers to product $A$ (a proof is available upon request), tainting FI 1's advice and undermining any advantage in offering a full line of financial services. This might explain why some one-stop FIs have failed to capture gains

\footnotetext{
${ }^{27}$ How realistic is the notion of market power among financial intermediaries? "A handful of familiar names - Citigroup, J.P. Morgan Chase, Goldman Sachs, Merrill Lynch dominates these businesses, either because it takes a huge investment to build them, or because only top names are trusted. Yet only Citigroup offers corporate and institutional clients the full range of services..." (The Economist, April 4th, 2002). Since the publication of this Economist article another one-stop bank has formed following the merger of J.P. Morgan Chase with Bank One.
} 
from consolidation and why several of them have recently decided to divest some of their units. Recent examples include American Express, who plans to spin off its financial advisory unit (acquired in 1983), Citigroup, who is disposing of its life insurance arm, and Morgan Stanley, who intends to spin off its Discover card unit. ${ }^{28}$ Although an extension of our model that allows for cost differences in the provision of services would clearly be interesting, it is beyond the scope of this paper.

\section{Unobservable investments in information provision}

In the previous sections we assume that customers are able to verify that the bank had made the necessary investment to provide them with reliable information. However, these investments may be difficult to verify in reality, in which case, banks' investments in information provision are subject to moral hazard. Banks will invest in information provision if and only if doing so leads to higher profits, while customers will only infer the investment has been made when the bank profits from the investment. As a consequence, the nature of the equilibrium is modified.

\footnotetext{
${ }^{28}$ In the American Express divestiture, advisers were said to look forward to independence, "because they have been discouraged from selling anything other than American Express products" ("American Express Plans to Spin Off Advisory Unit; Strategic Reversal Reflects Broader Industry Rethinking Of Financial Supermarkets," by Robin Sidel, Jeff D. Opdyke and Ruth Simon, Wall Street Journal, February 2, 2005). We are grateful to Douglas Diamond for pointing out this potential limit on the size of financial conglomerates.
} 
A natural question that then arises is what impact the observability of information provision services has on the industry. This question becomes even more salient when we discuss the nature of independent financial advisors, advisors that are separate from banks and who may or may not be providing "good" information.

\subsection{Unobservable investments with competition between spe- cialized FIs}

The basic timing of the game remains the same, except that the stage 1 investment in information provision is unobservable. For brevity, we will only focus on the case of competition between specialized banks such that FI $A$ is the price leader.

Consider the equilibrium in which FI $B$ invests in information acquisition at cost $f$ and provides advice to all customers. If investment is unobservable, FI $B$ may find that it is more profitable to save on the cost $f$ by not investing in information acquisition and simply making uninformed recommendations. In this situation, to make sure that FI $B$ does have the right incentive to invest in information acquisition, the following incentive constraint must hold:

$$
(1-q) p_{B}-f>p_{B}-q \rho
$$

To understand this constraint, note that the highest payoff FI $B$ can get by deviating and giving uninformed advice follows from always recommending 
product $B$ (since the beliefs of customers are held fixed). In that case FI $B$ always sells product $B$ at price $p_{B}$, but it pays a reputation cost on the fraction $q$ of type- $A$ customers. On the other hand, if FI $B$ does invest in information it is able to recommend product $B$ only to well-matched customers and thus avoids paying a reputation cost for poor advice. This incentive constraint puts an upper bound on $p_{B}$ of $\rho-\frac{f}{q}$. Notice that this is strictly lower than the upper bound for credible information provision when investment in information is observable $(\rho)$. Adding the participation constraint

$$
(1-q) p_{B}-f \geq 0
$$

and setting $p_{B}$ equal to its upper bound, $\rho-\frac{f}{q}$, then requires that

$$
\rho \geq \frac{f}{(1-q) q}
$$

for information provision to be credible in equilibrium. This condition on the reputation cost is strong. In particular, in the interval for $\rho,\left(\frac{f}{(1-q)}, \frac{f}{(1-q) q}\right)$, information would be provided when investment is observable but would not be provided under unobservable investment.

Similarly, in equilibria in which FI $A$ provides information we can derive an incentive constraint for FI $A$ by substituting $1-q$ for $q$ in Eq. (6) and setting FI $A$ 's price equal to the maximum of this interval, $\rho-\frac{f}{1-q}$. The participation constraint for FI $A$ is not symmetric, however, since FI $A$ 's payoff from not investing in information is positive: $(2 q-1) \Delta$. Thus, the 
participation constraint reduces to:

$$
q p_{A}-f \geq(2 q-1) \Delta \quad \Longrightarrow \rho \geq \frac{f}{(1-q) q}+\frac{(2 q-1) \Delta}{q}
$$

As in the case of observable investment, an equilibrium that has FI $A$ investing in information only occurs for higher reputation costs $\rho$. It is also clear that the cutoff for which there are equilibria such that either FI $A$ or FI $B$ provide information is higher here than in the case of observable investment (where it was $\left.\frac{f}{q}+\frac{(2 q-1) \Delta}{q}\right)$.

Note also that now there is always an equilibrium where no firm invests in information. This is clear when we look at the incentive constraint. If the FI does not invest in information and the customers know this, it receives some nonnegative payoff $\tilde{\pi}$. By deviating and investing in information, given that customers believe it will not provide any, its payoff will be $\tilde{\pi}-f$. We refer to this as the "Cassandra effect," since the FI may have valuable information to reveal, but no customer is listening.

In sum, the set of equilibria resembles that for observable information acquisition with two main differences. First, there is a larger interval over which no information provision is the unique equilibrium. Second, due to the "Cassandra effect," no information provision is always an equilibrium. 


\subsection{Independent financial advisors}

In the negotiations leading up to the $\$ 1.4$ billion settlement between Wall Street investment banks, New York State Attorney General Elliot Spitzer, and the SEC, an important proposal for resolving conflicts of interest of investment banks' "sell-side" analysts was the creation of a fully independent research entity that would employ these analysts. Although this idea was eventually shelved, separating financial advice from the sale of financial products seems like a simple and appealing solution to the kinds of conflicts of interest we have considered so far. ${ }^{29}$ Two forms of separation may be envisioned: a limited form, where each bank sets up so-called "Chinese walls" between analysts and sales departments $;{ }^{30}$ or a more radical form, where in-house financial analysts are spun off into full-fledged independent financial advisors (IFAs). ${ }^{31}$ Currently, only the former type of separation is required, although the Chinese walls that had been in place all along (but had been easily circumvented) have now been significantly enhanced under the Sarbanes-Oxley Act and the settlement with Elliot Spitzer.

\footnotetext{
${ }^{29}$ In the final settlement it was only agreed that $\$ 450$ million out of the $\$ 1.4$ billion, would be set aside to fund independent research over a five-year period (see "Regulators Set Accord with Securities Firms, But Some Issues Persist," by Randall Smith, Wall Street Journal, December 23, 2003).

${ }^{30}$ Demski, Lewis, Yao, and Yildirim (1999) study this type of separation in the context of firms that may breach their clients proprietary information.

${ }^{31}$ We specifically define IFAs as advisory firms that don't sell financial products; in the U.K., IFAs may sell financial products (their independence is defined by not being owned by a financial product provider). Interestingly, a study by the U.K.'s Financial Service Authority and Charles River Associates (Laslett, R., Wilsdon, T., Malcolm, K., 2001) finds that "There is significant bias in the advice" of these types of financial advisors on some of the products they sell.
} 
Some of the key issues in the negotiations with Elliot Spitzer concerned the quality of financial advice under an independent entity, analysts' incentives to perform the necessary research, and the form of analyst compensation. It turns out that our analysis here can shed light on these core issues ${ }^{32}$. In particular, in our model the separation of analysts into IFAs can be strictly beneficial to the financial intermediaries. In addition, as we now illustrate, it is generally easier to create incentives for IFAs to acquire costly information and to credibly provide advice than for in-house analysts. As in the previous section, we limit our focus to the case of competition between two differentiated specialized banks.

The fact that financial intermediaries will benefit from credible information provision by IFAs is easy to see. Suppose that the financial advisor has the correct incentives to tell the truth, ${ }^{33}$ then customers have perfect information before they approach the banks. As shown earlier in the paper, when specialized banks compete, profits are larger under full information than when information must be provided by the banks directly. The banks charge lower prices when they must provide their own information in order to credibly convey that information. In either case, the total surplus is

\footnotetext{
${ }^{32}$ Although the type of conflicts of interest that financial analysts face are not exactly the type we model here, we believe that our analysis can shed light on the similar core issues that arise in this context, in particular, the issues relating to incentives for IFAs to produce good quality research and to truthfully report their findings.

${ }^{33}$ This can be easily accomplished if the independent financial advisor charges a fixed amount for each customer, but suffers a positive reputation cost if she lies. Alternatively, the advisor may be paid a fixed amount (irrespective of the number of customers) by an FI, but still suffer some reputation cost (such as a dismissal when customers complain).
} 
the same since all customers match perfectly, although consumer surplus is clearly lower when financial advice is delivered separately.

To see why IFAs have better incentives for information acquisition when investment in information provision is unobservable, note that the incentive constraint $^{34}$ for IFAs is given by

$$
\rho_{I} \geq \frac{f}{1-q}
$$

where $\rho_{I}$ is the reputation cost of the IFA. Indeed, if the IFA does not invest in information it saves $f$ but it incurs a reputation cost of $\rho_{I}(1-q)$. If $\rho_{I}=\rho$, we therefore observe that the IFAs will provide information for the same range of parameters as specialized banks with observable investments. ${ }^{35}$ That is, the IFAs will provide information in some cases when specialized banks with unobservable investments do not, namely, $\rho \in\left(\frac{f}{(1-q)}, \frac{f}{(1-q) q}\right)$. In this case, IFAs help the specialized banks by revealing information that the banks cannot, as well as by allowing the banks to extract more rents. As a caveat, however, the reputation cost $\rho_{I}$ may be arguably less than $\rho$, due to the fact that there is much less at stake in a continuing relationship between an IFA and a customer. This could reduce the provision of information by IFAs relative to specialized banks. We also note that for all parameter values there exists a Cassandra effect equilibrium in which the IFA does not invest

\footnotetext{
${ }^{34}$ In the constraint, we implicitly assume the type of fixed payment-per-customer compensation scheme mentioned in the previous footnote.

${ }^{35}$ In addition, should there be competition between specialized FIs that offer the same product (say two FI $B$ ), then even when $\rho \geq \frac{f}{1-q}$, neither will have an incentive to invest in information as all the gains from information provision will then be dissipated ex post.
} 
in information, as before.

\section{Conclusion}

Our paper considers a situation in which financial intermediaries have better information about which financial products are best for their customers. They gain this informational advantage as a result of their continuous presence in financial markets, their knowledge of the latest financial innovations, and their ability to identify customer profiles. In such an environment financial services companies do not sell simply financial products; they may also provide financial advisory services. An obvious issue that arises in this context is the possibility of misselling financial products. Financial services companies face a fundamental conflict of interest problem: should they truthfully inform a client that another firm offers a product that better suits the client's needs or should they try to sell one of their own products? It would seem that when advice is tied to the sale of particular products this advice is likely to be tainted. As we show, however, it is not always the case that information is only credible if it is given by an independent institution. When there is sufficient competition or consolidation (into one-stop banks), financial services companies can overcome this conflict of interest problem.

To summarize, our analysis of conflicts of interest in financial-advisory services by FIs uncovers several key findings:

- Competition fosters information provision and reduces conflicts of inter- 
est - The fact that a specialized FI has incentives to provide untainted advice may be surprising, since the FI will always lose the customers that are not of its type to its competitor. Nevertheless, if we consider the starting point a situation in which absent information an FI will obtain no customers, providing information can differentiate one's products and increase market share.

- Reputation costs place upper bounds on the rents financial intermediaries may earn - Credible information provision comes at a cost, and that cost is lower profits.

- One-stop banks can provide information credibly and extract large rents when they have market power, provided that margins are similar on their products - One-stop banks can exert market power and credibly charge high prices without needing to hoodwink customers about particular products or services. This is an alternative justification for consolidation in the financial services industry beyond traditional economies of scope. A limit to one-stop banks' ability or willingness to provide information credibly, however, is the bank's capacity to secure substantially larger margins on some of its products. Larger margins would again tempt the bank to steer customers to specific products and undermine the credibility of one-stop banks' advice. These banks may then be tempted to spin off their less profitable units.

- Financial intermediaries may benefit, at the expense of customers, from 
separating advice from sales. The ability of independent financial advisers to provide information credibly results in greater product differentiation, which could allow FIs to extract higher margins from customers.

It would be interesting to extend this line of research in a dynamic direction in order to quantify the potential reputation costs that banks may incur. Another aspect that is worth further examination is allowing for heterogeneity in customers' knowledge of their types. With the advent of the internet and private banking, it is probable that certain clients have better information about which investments best match their needs. Our results in this context suggest that if customers have more information, market power of FIs and hence rents may actually increase, making this topic quite relevant to current policy discussions.

\section{Mathematical appendix}

\section{A.1. Monopoly banking}

\section{A.1.1. Specialized monopoly (Proposition 1)}

We first examine the case of a monopoly that specializes in product $A$. If the customer does not purchase at FI $A$, he receives a utility of zero and the bank makes zero profits. FI $A$ can make two statements, "recommend product $A$ " $(\hat{A})$ and "don't recommend product $A$ " $(\sim \hat{A})$. Lying when the customer purchases the product costs the FI $\rho$ per customer. Note that this 
proof is quite similar to though simpler than that of competing specialized banks, which we analyze in detail in the next section. Hence, we only sketch the proof here. We consider only pure strategies for the customers, using assumption A2.

- It can never be that customers who hear $\hat{A}$ choose $\sim A$ and customers who hear $\sim \hat{A}$ choose $A$. If $p_{A}>\rho$, then the FI would announce $\sim \hat{A}$ always. By the Cho-Kreps intuitive criterion, the probability of hearing $\hat{A}$ given type $\sim A(P(\hat{A} \mid \sim A))$ equals zero. Hence, a customer who hears $\hat{A}$ will always choose $A$ and type- $A$ would deviate since $p_{A} \leq R$. If $p_{A}<\rho$, there should be full revelation, but then upon hearing $\hat{A}$, the customer prefers $A$.

- When customers who hear $\hat{A}$ choose $A$ and customers who hear $\sim \hat{A}$ choose $\sim A$, then if $p_{A}<\rho$ the FI will fully reveal. However, since $\rho<r$ from $\mathbf{A 1}$, a customer hearing $\sim \hat{A}$ will always choose $A$ and there is no equilibrium. When $p_{A}>\rho$, the equilibrium will be nonrevealing, with the additional requirements that $p_{A}<q R+(1-q) r$ and (using Cho-Kreps) $p_{A}>r$.

- When customers who hear $\hat{A}$ choose $A$ and customers who hear $\sim \hat{A}$ choose $A$, there is a fully revealing equilibrium when $p_{A}<r$.

- Lastly, when customers who hear $\hat{A}$ choose $\sim A$ and customers who hear $\sim \hat{A}$ choose $\sim A$, we have partially revealing equilibria, where 
type- $A$ and type $\sim A$ mix their strategies. These are possible when $p_{A}>\max [r+P(A \mid \hat{A}) \Delta, r+P(A \mid \sim \hat{A}) \Delta]$. The minimum of this maximum is $q R+(1-q) r$ (we derive a very similar result in the proof of Lemma 4 below).

The results of the signaling game give us a profit function for every possible value of $p_{A}$. It is easy to see that there are two possible prices that could maximize the FI's profit: $p_{A}=r$, which yields $\pi_{A}=r$, and $p_{A}=q R+(1-q) r$, which yields $\pi_{A}=r+q \Delta-(1-q) \rho$. Hence, since $q>\frac{1}{2}$, the highest profits result when FI $A$ sets $p_{A}=q R+(1-q) r$ and does not reveal any information.

The signaling game for a monopoly FI $B$ is exactly the same, except that $1-q$ is substituted for $q$. Hence, there are two possible prices that could maximize the FI's profit: $p_{A}=r$, which yields $\pi_{A}=r$, and $p_{A}=(1-q) R+q r$, which yields $\pi_{A}=r+(1-q) \Delta-q \rho$. FI $B$ chooses the latter price when the reputation cost is not too high, $\rho<\frac{1-q}{q} \Delta$.

\section{A.1.2. One-stop monopoly (Proposition 2)}

When information revelation is possible, the one-stop bank engages in a signaling game in which it can recommend product $A$ or product $B$. The reputation cost $\rho$ is incurred when the one-stop bank lies to the customer and the customer makes a purchase (of either product). Again, since this proof is quite similar to the one above and to the competing specialized bank proof (which we go over in detail), we only summarize the main points. 
First, there can never be any equilibrium such that customers who hear $\hat{A}$ choose $B$ and customers who hear $\hat{B}$ choose $A$. When customers who hear $\hat{A}$ choose $A$ and customers who hear $\hat{B}$ choose $A$, there is a fully revealing equilibrium in which $p_{A}-p_{B}<-\Delta$. When customers who hear $\hat{A}$ choose $B$ and customers who hear $\hat{B}$ choose $B$, there is a fully revealing equilibrium in which $p_{A}-p_{B}>\Delta$. Finally, when customers who hear $\hat{A}$ choose $A$ and customers who hear $\hat{B}$ choose $B$, there are two ranges of equilibria: ${ }^{36}$ when $-\rho<p_{A}-p_{B}<\rho$, the equilibrium is fully revealing and if $\rho<(2 q-1) \Delta$, then when $\rho<p_{A}-p_{B}<(2 q-1) \Delta$, the equilibrium is nonrevealing with both types saying $\hat{A}$.

Since prices can never be larger than $R$ without violating individual rationality, the maximum profits from setting prices in the intervals $p_{A}-p_{B}<-\Delta$ and $p_{A}-p_{B}>\Delta$ is $r$. Maximum profits from setting prices in the interval $\rho<p_{A}-p_{B}<(2 q-1) \Delta$ come from setting $p_{A}=R$ (and $\left.p_{B} \geq R-(2 q-1) \Delta\right)$, which yields profits $R-(1-q) \rho$. In the interval $-\rho<p_{A}-p_{B}<\rho$, setting $p_{A}=p_{B}=R$ yields profits of $R$, which maximizes profits in the interval and overall.

\footnotetext{
${ }^{36}$ Note that there doesn't exist an information revelation equilibrium for certain parameter values because we do not allow for mixed strategies on the part of customers here due to assumption A2. If the FI sets prices in these regions $\left(-\Delta<p_{A}-p_{B}<-\rho\right.$ and $\left.\max [\rho,(2 q-1) \Delta]<p_{A}-p_{B}<\Delta\right)$, it is straightforward to show that profits are lower than $R$. In order to realize profits of $R$ (which are the maximum), the firm must tell the truth (to save on the reputation cost) and the customers must follow the firm's advice (to maximize their valuations). Clearly, this is impossible in these intervals.
} 


\section{A.2. Proof of Proposition 3 (Full information)}

Whatever the price set by $A$, if $B$ undercuts it by setting $p_{B}<p_{A}-\Delta$, both type- $A$ and type- $B$ customers prefer to purchase product $B$, yielding profits $\pi_{A}=0$ and $\pi_{B}=p_{B}\left(\right.$ and FI $B$ should set $p_{B}$ such that $\left.p_{B}=p_{A}-\Delta\right)$. On the other hand, if $p_{A}-\Delta<p_{B}<\min \left(p_{A}+\Delta, R\right)$, type- $A$ customers prefer product $A$ and type- $B$ customers prefer product $B$, yielding profits $\pi_{A}=q p_{A}$ and $\pi_{B}=(1-q) p_{B}\left(\right.$ and FI $B$ should set $p_{B}$ such that $\left.p_{B}=\min \left(p_{A}+\Delta, R\right)\right)$. Finally, setting $p_{B}>p_{A}+\Delta$ would yield $\pi_{B}=0$, so FI $B$ will never price in this range.

FI $A$ 's strategy will be to set a price such that $B$ prefers not to undercut $A$. For this to occur, $B$ 's profits have to be at least as large by choosing a price in the $\left(p_{A}-\Delta, \min \left(p_{A}+\Delta, R\right)\right)$ range. That is,

$$
(1-q) \min \left(p_{A}+\Delta, R\right) \geq p_{A}-\Delta .
$$

The optimal choice of $A$ happens to depend upon some conditions on the parameters:

- Case 1: $q R<2 \Delta$.

$A$ could choose to set a price $p_{A}<r$ or $p_{A}>r$.

- If FI $A$ chooses a price such that $p_{A} \leq r$, then $p_{A}+\Delta \leq R$. Since $q R<2 \Delta$, we have $q\left(p_{A}+\Delta\right)<2 \Delta$ and therefore, adding $p_{A}$ to both sides and rearranging, $p_{A}-\Delta \leq(1-q)\left(p_{A}+\Delta\right)$. So, (7) is 
satisfied and $A$ realizes profits $\pi_{A}=q p_{A}$. FI $A$ profits are locally maximized for $p_{A}=\min \left(r, \frac{2-q}{q} \Delta\right)$. Since $q R<2 \Delta$, dividing by $q$ and subtracting $\Delta$ yields that the minimum is reached for $p_{A}=r$.

- If $p_{A}>r$, then $p_{A}+\Delta>R$ and $p_{B}=R$. FI $A$ will therefore choose the maximum price that satisfies $(7)$, which is now $p_{A}=$ $\min [(1-q) R+\Delta, R]$

If $\min [(1-q) R+\Delta, R]=R$, then FI $A$ profits are larger in the $p_{A}>r$ range, as $R>r$.

If instead, $\min [(1-q) R+\Delta, R]=(1-q) R+\Delta$, this is also the case, since $q R<2 \Delta$ implies $(1-q) R+2 \Delta>R$ and therefore $(1-q) R+\Delta>r$.

- Case 2: $q R>2 \Delta$.

Proceeding in the same way as in Case 1, consider the two strategies for FI $A$.

- If FI $A$ chooses a price such that $p_{A} \leq r$, then $p_{A}+\Delta \leq R$, and condition $(7)$ becomes $(1-q)\left(p_{A}+\Delta\right) \geq p_{A}-\Delta$, which is equivalent to $p_{A} \leq \frac{2-q}{q} \Delta$. Since $q R>2 \Delta$ implies $r>\frac{2-q}{q} \Delta$, the best strategy for FI $A$ within the $p_{A} \leq r$ range of prices is to set $p_{A}=\frac{2-q}{q} \Delta$.

- If $p_{A}>r$, then, because $q R>2 \Delta$ implies $r>(1-q) R+\Delta$, we have $p_{A}-\Delta>(1-q) R$, condition (7) is never satisfied, and it is never optimal for FI $A$ to choose a price $p_{A}>r$. 
- Consequently, the best strategy in Case 2 is to choose the best price for $p_{A} \leq r$, that is, $p_{A}=\frac{2-q}{q} \Delta$, which proves proposition 3 .

\section{A.3. Proof of Lemma 4}

We will consider successively the different possible equilibria, which can be completely ordered by customer strategies $(a=1, b=1 ; a=0, b=1$; $a=1, b=0$; and $a=0, b=0)$ since assumption A2 allows us to disregard equilibria with interior values for $a$ or $b$.

- Case $1(a=1, b=0)$

Replacing these values in Eqs.(2) and (3), we obtain $\Delta \pi_{A}(A)>0$ and $\Delta \pi_{A}(B)>0$, and there is full revelation with all customers buying $A$. The condition $\Delta U_{A}(\widehat{A})>0$ implies then $p_{A}<p_{B}+\Delta$, while $\Delta U_{A}(\widehat{B})<$ 0 implies the stronger condition $p_{A}<p_{B}-\Delta$. As a consequence, the necessary and sufficient condition for this equilibrium to occur is $p_{A}<p_{B}-\Delta$, as stated in part 1 of the Lemma.

- Case $2(a=1, b=1)$

Replacing these values in Eqs. (2) and (3), we obtain $\Delta \pi_{A}(A)=p_{A}$ and $\Delta \pi_{A}(B)=-p_{A}+\rho$. As a consequence two cases are to be considered: $p_{A}<\rho$ and $p_{A}>\rho$ (equality is ruled out by assumption A2). In the first case, the equilibrium is fully revealing and the conditions for $a=1$ and $b=1$ to be a solution are that $\Delta U_{A}(\widehat{A})>0$ and $\Delta U_{A}(\widehat{B})>0$ are fulfilled, so that $p_{B}-\Delta<p_{A}<p_{B}+\Delta$. Using $\Delta>\rho$ (from 
assumption A1) allows us to establish part 2 of the lemma. On the other hand, if $p_{A}>\rho$, the sign of $\Delta \pi_{A}(B)$ is negative and there is no equilibrium revelation as every agent is given the message $\widehat{A}$. As a consequence, the conditional probability $p(A \mid \widehat{A})=q$, and, by ChoKreps $p(B \mid \widehat{B})=1$. Conditions $\Delta U_{A}(\widehat{A})>0$ and $\Delta U_{A}(\widehat{B})>0$ imply $\Delta U_{A}(\hat{A})=(2 q-1) \Delta-p_{A}+p_{B}>0$ and $\Delta U_{A}(\widehat{B})=\Delta-p_{B}+p_{A}>0$, proving part 3 of the lemma.

- Case $3(a=0, b=1$, zero profits for FI $A)$

i) Replacing these values in Eqs. (2) and (3), we obtain $\Delta \pi_{A}(A)=$ $\Delta \pi_{A}(B)=0$. These conditions permit FI $A$ to choose any strategy. First, FI $A$ may play a mixed strategy, with $\alpha, \beta \in(0,1)$. The inequalities $\Delta U_{A}(\hat{A})<0$ and $\Delta U_{A}(\widehat{B})>0$ hold for these values of $\alpha$ and $\beta$ if and only if:

$$
p_{A}>p_{B}+\max [(2 P(A \mid \hat{A})-1) \Delta,-(2 P(B \mid \hat{B})-1) \Delta] .
$$

By definition, for $(\alpha, \beta) \neq(0,0)$ and $(\alpha, \beta) \neq(1,1)$ :

$$
P(A \mid \hat{A})=\frac{\alpha q}{\alpha q+\beta(1-q)} \text { and } P(B \mid \hat{B})=\frac{(1-\beta)(1-q)}{(1-\alpha) q+(1-\beta)(1-q)}
$$

Define $\psi(\alpha, \beta)$ by:

$$
\psi(\alpha, \beta) \equiv \max \left[2 \frac{\alpha q}{\alpha q+\beta(1-q)}-1,1-2 \frac{(1-\beta)(1-q)}{(1-\alpha) q+(1-\beta)(1-q)}\right] .
$$


It can be easily shown that for $\alpha>\beta, \psi(\alpha, \beta)=2 \frac{\alpha q}{\alpha q+\beta(1-q)}-1$. This expression is increasing in $\alpha$, implying that the minimum occurs when $\alpha=\beta$, for which $\psi(\alpha, \alpha)=2 q-1$. Similarly, if $\beta>\alpha, \psi(\alpha, \beta)=1-$ $2 \frac{(1-\beta)(1-q)}{(1-\alpha) q+(1-\beta)(1-q)}$. This expression is increasing in $\beta$, and its minimum occurs when $\beta=\alpha$, for which $\psi(\beta, \beta)=2 q-1$. Finally, the maximum of $\psi(\alpha, \beta)$ is 1 .

The necessary and sufficient condition for an equilibrium where FI $A$ uses a mixed strategy regarding revelation while customers buy $B$, is $p_{A}>p_{B}+\psi(\alpha, \beta)$. Using the minimum and maximum values for $\psi(\alpha, \beta)$ establishes part $4 \mathrm{a}$ of the lemma and the range of values $(\alpha, \beta)$ over which the mixed strategy equilibrium holds.

ii) If, instead, FI $A$ 's strategy is ( $\alpha=1, \beta=1)$, announcing systematically $\widehat{A}, P(B \mid \widehat{B})$ is defined by out-of-equilibrium beliefs, and for each set of out-of-equilibrium beliefs we obtain a different equilibrium. Symmetrically, if $(\alpha=0, \beta=0), P(A \mid \hat{A})$ will be defined by out-of-equilibrium beliefs. Since on the equilibrium path the condition $p_{A}>p_{B}+(2 q-1) \Delta$ holds, we now have the second and third parts of part 4 of the lemma.

iii) Combining the conclusions of i) and ii) we find that if the condition $p_{A}>p_{B}+\Delta$ holds, any FI $A$ strategy $(\alpha, \beta \in[0,1])$ is an equilibrium in which all customers purchase $B$. This is part 5 of the lemma.

- Case $4(a=0, b=0)$ 
This is never an equilibrium. Indeed, it implies $\Delta U_{A}(\widehat{A})<0$ and $\Delta U_{A}(\widehat{B})<0$, so that Eqs. (2) and (3) become $\Delta \pi_{A}(A)=-p_{A}+\rho$ and $\Delta \pi_{A}(B)=p_{A}>0$. Therefore, two cases are to be considered. If $\rho>p_{A}$, the equilibrium is fully revealing; if $\rho<p_{A}$, the FI only announces $\widehat{B}$ but the Cho-Kreps criterion allows us to infer that $P(A \mid \widehat{A})=1$. So, whatever the case, replacing $P(A \mid \widehat{A})=1$ in expressions (4) and (5) leads to $\Delta U_{A}(\widehat{A})+\Delta U_{A}(\widehat{B})=\Delta(2 P(B \mid \widehat{B})) \geq 0$, which is a contradiction.

\section{A.4. Proof of Proposition 5 (Competing specialized banks, FI $A$ is the price leader)}

1) First assume that $p_{B}>\rho+\Delta$. Then the only price-region in which FI $B$ makes positive profits is $p_{B}<p_{A}-(2 q-1) \Delta$. In this region FI $A$ makes zero profits. Therefore FI $A$ must set $p_{A}$ so that $p_{B}<\rho+\Delta$. It can do this by setting $p_{A}-(2 q-1) \Delta<\rho+\Delta$, or $p_{A}<\rho+2 q \Delta$. For $\rho<p_{A}<\rho+2 q \Delta$, prices are such that the equilibrium is non-revealing and all customers purchase $A$, or partially revealing and all customers purchase $B$. FI $B$ sets its price so that the second interval obtains, which then implies that FI $A$ sets its price such that $p_{A}<\rho$. However, if $\rho<(2 q-1) \Delta$ and FI $A$ sets its price equal to $(2 q-1) \Delta$, FI $B$ cannot make positive profits at any price.

For $p_{A}<\rho$, FI $A$ fully reveals and everyone purchases at FI $A\left(p_{B}>\right.$ $\left.p_{A}+\Delta\right)$ or FI $A$ fully reveals and everyone purchases at the FI that matches 
their type $\left(p_{B}<p_{A}+\Delta\right)$. Clearly, the latter is preferable for FI $B$, which proves our conjecture.

2) First consider the situation in which $p_{A}>\rho+\Delta$. Here FI $B$ clearly does not choose to be in the partially revealing interval where it realizes zero profits $\left(p_{B}>p_{A}-(2 q-1) \Delta\right)$. However, the other two regions involve FI $A$ obtaining zero profits, so it must be that $p_{A}<\rho+\Delta$.

Now consider $\rho+(2 q-1) \Delta<p_{A}<\rho+\Delta$. Here there is one price-region in which both firms make positive profits: $p_{A}-\Delta<p_{B}<\rho$. Information is credibly revealed and customers follow the advice. The highest profits for FI $B$ are obtained by setting its price at the maximum value over this interval $(\rho)$ and are given by $\pi_{B}=(1-q) \rho$. But, for the price-region $\rho+(2 q-1) \Delta<$ $p_{A}<\rho+\Delta$, FI $B$ does not reveal customer types and all customers purchase at FI $B$. Profits are maximized for FI $B$ by choosing the highest price in the interval $p_{A}-(2 q-1) \Delta$, which yields expected profits $p_{A}-(2 q-1) \Delta-q \rho$. These profits are larger than $(1-q) \rho$ (taking into account that we are in the region $\left.\rho+(2 q-1) \Delta<p_{A}<\rho+\Delta\right)$, which means that $p_{A}$ should be set even lower.

Lastly, setting $p_{A}<\rho+(2 q-1) \Delta$ can produce two possible responses from FI $B$. If FI $B$ sets $p_{B}=p_{A}-\Delta$, FI $B$ fully reveals information and attracts all customers. If FI $B$ sets $p_{B}=\rho$, it fully reveals customer types and attracts the well matched customers at this higher price. FI $A$ only makes positive profits in this second region, so the solution has FI $A$ setting its price so that FI $B$ prefers this choice. 
3) The proof has the same flavor as that of part 2), but we need to verify in which information revelation regime FI $A$ is located, and whether customers might approach FI $A$ first instead. Consider the situation in which $p_{A}>\rho+\Delta$. FI $B$ does not choose to be in its partially revealing interval $\left(p_{B}>p_{A}-(2 q-1) \Delta\right)$ since it can be shown that customers then always go to FI $A$ and purchase there, leaving FI $B$ with zero profits. FI $B$ chooses to be in one of the other two regions, both of which involve FI $A$ getting zero profits, so it must be that $p_{A}<\rho+\Delta$.

Now consider $\rho+(2 q-1) \Delta<p_{A}<\rho+\Delta$. Unlike in the previous interval, there is one region in which FI $B$ fully reveals information and customers follow its advice: $p_{A}-\Delta<p_{B}<\rho$. In this region both FIs make positive profits (in this region FI $A$ is in the partial revelation regime $-p_{B}<\rho$ and $\rho+(2 q-1) \Delta<p_{A}$ imply $p_{B}+(2 q-1) \Delta<p_{A}$ - so all customers visit FI $B$ first). The highest profits for FI $B$ are obtained by setting its price at the maximum value for this interval $(\rho)$ and are given by $\pi_{B}=(1-q) \rho$. However again, the region above is a nonrevealing one, in which all customers approach FI $B$ first and purchase there. Profits are maximized for FI $B$ by choosing the highest price in the interval, $p_{A}-(2 q-1) \Delta$, which yields expected profits $p_{A}-(2 q-1) \Delta-q \rho$. These profits are larger than $(1-q) \rho$ (given we are in the region $\left.\rho+(2 q-1) \Delta<p_{A}<\rho+\Delta\right)$, which means that $p_{A}$ should be set even lower.

Lastly, we look at $p_{A}<\rho+(2 q-1) \Delta$. As before, if FI $B$ sets $p_{B}<p_{A}-\Delta$, FI $B$ fully reveals information and gets all of the customers. For the region 
$p_{A}-\Delta<p_{B}<\rho$, FI $B$ is in a fully revealing regime in which customers follow its advice. Note that for this range of $p_{B}$ it is weakly dominant for customers to approach FI $B$ first (in fact, the only time there is indifference is if FI $A$ is in a fully revealing regime as well). Therefore, both FI $A$ and FI $B$ make positive profits in this region. Consequently, FI $A$ would like to ensure that FI $B$ prefers this region. It is possible that FI $B$ may want to set its price even higher than $\rho$ here. If it does so, it will be in a partial revelation regime. Since it will make zero profits if customers approach it first, FI $B$ needs FI $A$ to be in a full revelation regime to make profits. For FI $A$ to be in a full revelation regime there are two possibilities.

The first possibility occurs when $\rho-(2 q-1) \Delta<p_{B}<\rho+\Delta$ and $p_{B}-\Delta<p_{A}<\rho$. Here it is clear that FI $A$ prefers to set $p_{A}$ as high as possible $(\rho)$ and FI $B$ can then follow by setting $p_{B}$ as high as possible $(\rho+\Delta)$. Notice here that FI $B$ is free-riding on the information of FI $A$ in order to set a higher price. However, profits for FI $A$ would be less than if it got prices higher and forced FI $B$ to be the information provider $(q \rho<$ $q \min [(1-q) \rho+\Delta, \rho+(2 q-1) \Delta])$.

The second possibility occurs when $p_{B}<\rho-(2 q-1) \Delta$ and $p_{B}-\Delta<p_{A}<$ $p_{B}+(2 q-1) \Delta$. The maximum return for FI $B$ would follow from setting $p_{B}=\rho-(2 q-1) \Delta$, in which case $p_{A}=\rho$; however, this is also dominated by the above equilibrium. 


\begin{tabular}{|c|c|c|c|}
\hline \multirow{5}{*}{ FI A } & \multicolumn{3}{|c|}{ FI B } \\
\hline & & No Info & Info \\
\hline & No Info & $(2 q-1) \Delta+p_{B}{ }^{N I, N I}, 0$ & $q(\rho+\Delta),(1-q) \rho-f$ \\
\hline & Info if $\rho>(2 q-1) \Delta$ & $q \rho-f,(1-q)(\rho-(2 q-1) \Delta)$ & $q(\rho+\Delta)-f,(1-q) \rho-f$ \\
\hline & Info if $\rho<(2 q-1) \Delta$ & $(2 q-1) \Delta-(1-q) \rho+p_{B}{ }^{I, N I}-f, 0$ & $q(\rho+\Delta)-f,(1-q) \rho-f$ \\
\hline
\end{tabular}

Fig. A1. Matrix for competition among specialized banks (B is the price leader).

\section{A.5. Equilibria when FI B is the price leader}

\section{A.5.1. Competition among specialized banks}

\section{Results}

The payoffs are given by the following matrix:

A few comments are in order when comparing this case to the one in which FI $A$ is the price leader. First, the (No Information, No Information) and the (Information if $\rho<(2 q-1) \Delta$, No Information) cases are now partially undetermined, since for any $p_{B}$ announced by FI $B$, FI $A$ will be able to attract all of the customers and leave FI $B$ with zero profits. For the sake of comparison, we assume that $p_{B}$ is the same in both cases $\left(p_{B}^{N I, N I}=p_{B}^{N I, I}\right)$. Second, the (Information, Information) case is more complex here, since FI $A$ 's advantage in ex ante preferences $\left(q>\frac{1}{2}\right)$ allows it to free-ride on FI $B$ in 
the sense that FI $A$ may keep its prices high and force FI $B$ to provide information to customers. Indeed, the equilibrium has FI $A$ partially revealing, FI $B$ fully revealing, and all customers approaching FI $B$ first and following FI $B$ 's advice.

Third, it is clear from the (Information, Information) case and the (No Information, Information) case that FI $A$ is able to use its role as a price follower to its advantage in achieving higher payoffs.

Finally, we find again that for a reputation cost that is tiny or equal to zero $\left(\rho<\frac{f}{1-q}\right)$, the unique equilibrium is that neither firm provides information. ${ }^{37}$ For medium reputation $\operatorname{costs}\left(\frac{f}{1-q}<\rho<\frac{(2 q-1) \Delta+p_{B}^{N I, N I}}{q}\right)$, the unique equilibrium is that only FI $B$ provides information. For large reputation costs, once again we find a possible multiplicity of equilibria such that either just one firm provides information or both firms employ mixed strategies. ${ }^{38}$

\section{Proof of the payoffs in Fig. A1 above:}

1) Only FI $B$ invests in information: As long as $p_{B}>\rho$, FI $A$ has an incentive to set its price just below $p_{B}+(2 q-1) \Delta$, which leads to zero profits for FI $B$. If $p_{B}<\rho$, FI $A$ must price below $p_{B}+\Delta$ in order to make positive profits. Therefore the equilibrium is $p_{B}=\rho, p_{A}=\rho+\Delta$.

2) Only FI $A$ invests in information: When $p_{B}>\rho-(2 q-1) \Delta$, the best response for FI $A$ is always to price slightly under $p_{B}+(2 q-1) \Delta$ and not reveal any information (always say $\hat{A}$ ). Since all customers then purchase $A$,

\footnotetext{
${ }^{37} \mathrm{As}$ in the case when FI A is the price leader, we assume $f<(1-q) \Delta$.

${ }^{38} \mathrm{As}$ in the case when FI A leads, vertical differentiation implies information revelation for a smaller range of parameters here.
} 
this yields profits of zero for FI $B$. If $\rho<(2 q-1) \Delta$, this is what occurs and the price of FI $B$ is undetermined, as any price yields zero profits. If $\rho>(2 q-1) \Delta$, then FI $B$ will set its price below $\rho-(2 q-1) \Delta$. FI $A$ has two options, setting a price of $p_{B}-\Delta$, fully revealing, and getting all of the customers, or setting a price of $\rho$, fully revealing, but sharing the customers. FI $B$ clearly prefers the second option and must set $p_{B}$ such that $p_{B}-\Delta<q \rho$ (FI $A$ prefers the second option). Since $\rho-(2 q-1) \Delta<q \rho+\Delta$, FI $B$ sets its price at $\rho-(2 q-1) \Delta$.

3) Both FIs invest in information: When $p_{B}>\rho+\Delta$, any price that FI $A$ charges that gives it positive profits gives FI $B$ zero profits.

When $\rho-(2 q-1) \Delta<p_{B}<\rho+\Delta$, we must look carefully at the possible best response of FI $A$ :

- If $p_{B}-\Delta<p_{A}<\rho$, FI $A$ fully reveals customer types, with customers taking its advice. Indeed, FI $B$ does the same (since $p_{A}-(2 q-1) \Delta<$ $\rho)$, so it does not matter where customers go first and the solution (restricting FI $A$ to this interval) is $p_{B}=\rho+\Delta$ with profits $(1-q)(\rho+\Delta)$ and $p_{A}=\rho$ with profits $q \rho$.

- If $\rho<p_{A}<p_{B}+(2 q-1) \Delta$, FI $A$ reveals nothing and the only possible chance for both to make positive profits is for FI $B$ to be in a fully revealing regime. Since the interval for $p_{A}$ implies that $p_{B}>p_{A}-(2 q-$ 1) $\Delta$, to observe a fully revealing regime we must have $p_{A}-(2 q-1) \Delta<$ $\rho$. Hence, a candidate solution here is $p_{B}=\rho$ with profits $(1-q) \rho$ and 
$p_{A}=\rho+(2 q-1) \Delta$ with profits $q(\rho+(2 q-1) \Delta)$.

- If $p_{A}>p_{B}+(2 q-1) \Delta$, FI $A$ is partially revealing. Hence, it will only choose this interval if FI $B$ is fully revealing. The maximum price for FI $B$ to fully reveal is $\rho$, which limits FI $A$ to a price of $\rho+\Delta$ (the profits are $(1-q) \rho$ and $q(\rho+\Delta)$ for FI $B$ and FI $A$, respectively).

- Lastly, if $p_{A}<p_{B}-\Delta$, FI $A$ fully reveals and attracts all of the customers. Hence, its profits are $p_{B}-\Delta$.

The profit of $p_{B}-\Delta$ for FI $A$ proves that there is a profitable deviation from the $p_{B}=\rho+\Delta$ candidate solution. Since FI $A$ prefers to set $p_{A}=\rho+\Delta$ (rather than $\left.p_{A}=\rho+(2 q-1) \Delta\right)$ and a deviation downward as before (to $\rho-\Delta)$ is impossible, the solution for this interval of $p_{B}$ is $p_{B}=\rho$ and $p_{A}=\rho+\Delta$.

Finally, any profit gained from FI $B$ setting $p_{B}<\rho-(2 q-1) \Delta$ is lower than when $p_{B}=\rho$ because of the lower price and the fact that FI $A$ either shares or takes all of the customers.

\section{A.5.2. Competition between a one-stop bank and specialized FI B, when FI $B$ is the price leader}

When FI $B$ is the price leader, results change in the information revelation game from when there were just two specialized banks competing. To see this assume that FI $B$ chooses some price $p_{B}$. In the environment in which no information is provided, the equilibrium is $p_{1 A}=\min \left[(2 q-1) \Delta+p_{B}, q R+\right.$ 
$(1-q) r]$ and $p_{1 B}>p_{B}$, with all profits going to the one-stop bank and all consumers purchasing product $A$. This solution is the same as when competition is between specialized FIs.

If, instead, customers know their type ex ante, the one-stop bank obtains all of the profits and consumers purchase the product that matches their type.$^{39}$ Here, the one-stop bank directly steals clientele from FI $B$ by undercutting it on product $B$. This differs from the specialized FI solution since the one-stop bank can't be given an incentive to split the customer base.

When FI 1 decides whether to provide information, the signaling game changes significantly from that of Section 4. First of all, the game for FI 1 can look like the game in which a one-stop bank has no competition if it undercuts FI $B$, setting $p_{1 B}=p_{B}-\delta$ (where $\delta$ is small). In this case we can apply the results from the signaling game of Proposition 2 to find the solution. It is straightforward to show that if FI 1 undercuts FI $B$, it will set $p_{1 A}=p_{1 B}+\rho=p_{B}-\delta+\rho$ and achieve profits of $p_{B}-\delta+q \rho$ when $\rho>(2 q-1) \Delta$, or set $p_{1 A}=p_{1 B}+(2 q-1) \Delta=p_{B}-\delta+(2 q-1) \Delta$ and achieve profits of $p_{B}-\delta+(2 q-1) \Delta-(1-q) \rho$ when $\rho<(2 q-1) \Delta$. This gives FI 1 weakly larger profits than a specialized FI $A$ realizes when FI $B$ does not provide information (compare with Fig. A1).

When FI $B$ provides information, however, it may choose $p_{B}$ strategically to avoid undercutting behavior and generate positive profits. Basically, it can

\footnotetext{
${ }^{39}$ Restricting attention to pure strategies, if $p_{B}>r, p_{1 A}=R$ and $p_{1 B}=p_{B}-\delta$ (where $\delta$ is small), while if $p_{B}<r, p_{1 A}=\Delta+p_{B}-\delta$ and $p_{1 B}=p_{B}-\delta$.
} 
FI B

\begin{tabular}{|c|c|c|c|}
\hline \multirow[b]{2}{*}{ FI 1} & & No Info & Info \\
\hline & No Info & $(2 q-1) \Delta+p_{B}{ }^{N I, N I}, 0$ & $q(\rho+\Delta),(1-q) \rho-f$ \\
\hline & Info if $\rho>(2 q-1) \Delta$ & $p_{B}^{I, N I}+q \rho-f, 0$ & $q\left(p_{B}{ }^{*}+\Delta\right)-f,(1-q) p_{B}{ }^{*}-f$ \\
\hline & Info if $\rho<(2 q-1) \Delta$ & $(2 q-1) \Delta-(1-q) \rho+p_{B}^{I, N I}-f, 0$ & $q(\rho+\Delta)-f,(1-q) \rho-f$ \\
\hline
\end{tabular}

Fig. A2. Matrix for competition between a one-stop and a specialized FI (B is the price leader).

choose $p_{B}$ such that it satisfies the incentive constraint of FI 1 to prefer not to undercut on product $B$. Using this logic and the solution from the case of competition between specialized banks FI $A$ and FI $B,{ }^{40}$ this implies that $p_{B}=\min \left[\rho, \frac{q}{1-q}(\Delta-\rho)\right]$ if FI 1 provides information and $\rho>(2 q-1) \Delta$, and $p_{B}=\rho$ otherwise. This yields the payoff matrix described below in Fig. A2.

Despite the differences in the potential strategies, we find equilibria that are similar to our previous ones. ${ }^{41}$ For $\rho<\frac{f}{1-q}$, the unique solution is that neither FI provides information. For larger values of $\rho$, there may either be one equilibrium such that only FI $B$ provides information, or three equilibria, namely, two pure strategy equilibria such that only one FI provides

\footnotetext{
${ }^{40}$ Note that in this case, one part of the no-undercutting constraint is that $\rho<p_{1 A}-$ $(2 q-1) \Delta$. This implies $(1-(1-q)(2 q-1)) \Delta>\rho$, which we assume to be true here.

${ }^{41}$ Also assuming that $p_{B}^{N I, N I}=p_{B}^{I, N I}$ as before.
} 
information and one mixed strategy equilibrium. ${ }^{42}$

\section{A.6. Robustness of the model to more general reputation costs}

In our model, a FI bears a reputation cost if i) it lies to a customer and ii) it profits from its lie because this lie leads the customer to purchase from it. Since other models of reputation costs are possible, we check here whether the model is robust to a more general specification of reputation costs. In order to do this we focus on the case in which FI $A$ is the price leader and FI $B$ is the firm that has invested in information provision. This is the main case in our model, as we have established in Proposition 6. We saw that the ex ante disadvantage of FI $B$ forced it into an information revelation role, which forms the basis of our main results.

We allow for two reputation costs. One reputation cost, $\gamma$, is incurred when the FI lies and misleads the customer into purchasing the wrong product. This occurs when FI $B$ tells a $B$-customer that he is type $A$ and the customer purchases $A$ (a case that entails no reputation cost in our model) and when it tells an $A$-customer that she is type $B$ and the customer purchases $B$ (a case that we cover in our model). The other reputation cost, $\eta$, is incurred when the FI lies but doesn't mislead the customer. This occurs when FI $B$ tells a $B$-customer that he is type $A$ and the customer purchases

\footnotetext{
${ }^{42}$ Specifically, if $\rho<q \Delta$, there is only one equilibrium in the high range (FI $B$ provides information). If $\rho>q \Delta$, for $\frac{f}{1-q}<\rho<\hat{\rho}$, there is only one equilibrium (FI $B$ provides information), while for $\rho>\hat{\rho}$ there are three equilibria (one such that only FI $B$ provides information, one such that only FI $A$ provides information, and one such that both FIs mix their strategies). Here we define $\hat{\rho}=\max \left[\frac{(2 q-1) \Delta+f}{q}, \frac{q \Delta-f}{q}\right]$.
} 


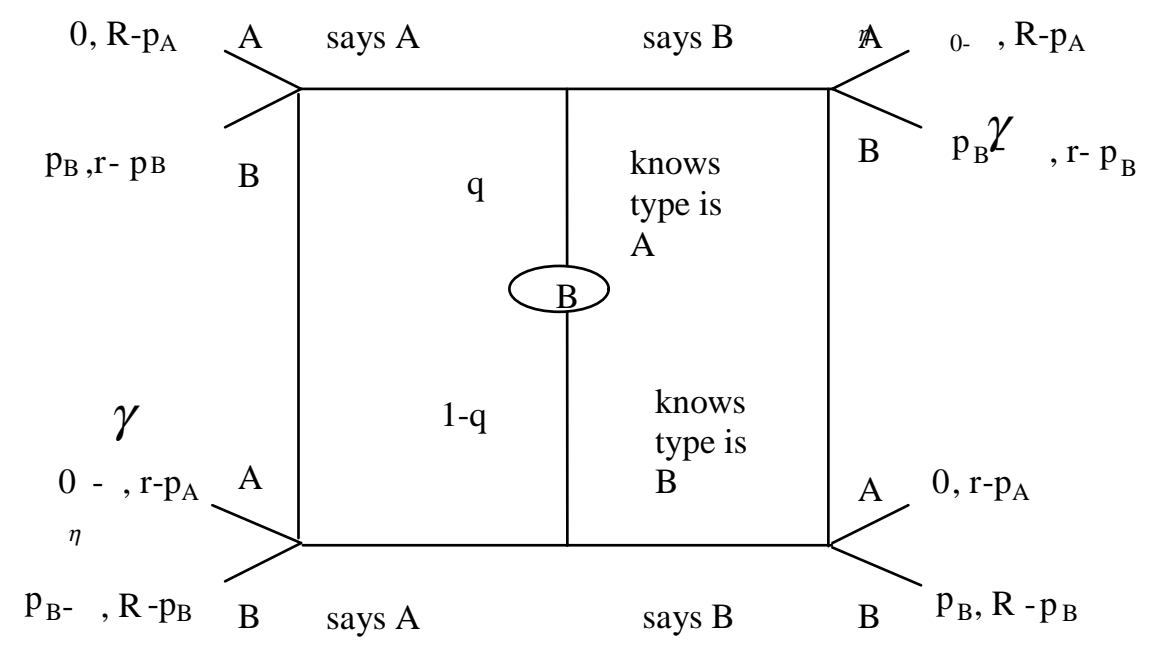

Fig. A3. The signaling game with general reputation costs.

$B$ and when it tells an $A$-customer that she is type $B$ and the customer purchases $A$. We assume that $\gamma>\eta$. This is represented in Fig. A3.

For this subsection, we abandon assumption A2. As we will see, there is a nontrivial partially revealing equilibrium that would be eliminated with assumption A2 (and leave no equilibria for a range of possible prices).

1. We begin by analyzing the signaling game for FI $B$. For brevity, when customers use pure strategies we only describe the equilibrium, as its derivation is quite similar to our previous analyses.

- When $p_{B} \leq p_{A}-\Delta$, FI $B$ fully reveals and all customers purchase $B$.

- When $p_{B} \geq p_{A}+\Delta$, FI $B$ fully reveals and all customers purchase 
A.

- When $p_{A}-\Delta \leq p_{B} \leq p_{A}+\Delta$ and $p_{B} \leq \gamma$, FI $B$ fully reveals and customers follow the advice.

- When $p_{A}-\Delta \leq p_{B} \leq p_{A}-(2 q-1) \Delta$ and $p_{B} \geq \gamma$, FI $B$ always says $\hat{B}$, and customers purchase $B$.

- When $p_{A}-(2 q-1) \Delta \leq p_{B} \leq p_{A}-\Delta$ and $p_{B} \geq \gamma$ there is one partially revealing equilibrium, such that FI $B$ is indifferent between saying $\hat{A}$ and $\hat{B}$ to an A customer, but always says $\hat{B}$ to a $B$ customer. Customers who hear $\hat{B}$ are indifferent between purchasing $A$ or $B$. Let $y$ equal the probability with which FI $B$ says $\hat{B}$ to an $A$ customer. The customer who hears $\hat{B}$ updates her probability of being type $B$ to equal $\frac{1-q}{1-q+y q}$. She is then indifferent when $p_{B}=p_{A}+\left(2\left(\frac{1-q}{1-q+y q}\right)-1\right) \Delta($ since $y \in[0,1]$, $\left.p_{B} \in\left[p_{A}-(2 q-1) \Delta, p_{A}+\Delta\right]\right)$. Customers who hear $\hat{A}$ know they are type- $A$, and since $p_{B} \geq p_{A}-\Delta$, they purchase $A$. In order to make FI B indifferent, the customer at $\hat{B}$ then chooses $B$ with probability $\frac{\eta}{\eta+p_{B}-\gamma}$ (which also implies that a necessary condition is $\left.p_{B} \geq \gamma\right)$. Profits from partially revealing are $(1-q)\left(\frac{\eta}{\eta+p_{B}-\gamma}\right) p_{B}$. Profits are decreasing in $p_{B}$ (using the assumption $\gamma>\eta$ ), meaning that FI $B$ has the incentive to set its price at the bottom of the interval.

2. Competition between FI $A$ and FI $B$ can also be analyzed in a similar 
way as before.

- First, we show that $p_{A}$ is below $\gamma+\Delta$. If it were above, there would be four possible information regimes: fully revealing such that all customers purchase $B\left(p_{B} \leq p_{A}-\Delta\right)$, nonrevealing such that all purchase $B\left(p_{A}-\Delta \leq p_{B} \leq p_{A}-(2 q-1) \Delta\right)$, partially revealing $\left(p_{A}-(2 q-1) \Delta \leq p_{B} \leq p_{A}+\Delta\right)$, and fully revealing such that all buy $A\left(p_{B} \geq p_{A}+\Delta\right)$. FI $B$ will never set the price so high that everyone purchases $A$, so we can focus on the first three intervals. The only interval in which FI $A$ makes positive profits is the partially revealing one. Hence, we will show, in a proof by contradiction, that FI $B$ can make larger profits by not pricing in that interval.

Suppose the profits from the partially revealing interval are larger than those of the nonrevealing interval. If FI $B$ sets its price in the nonrevealing interval, it will choose the highest element, $p_{A}-(2 q-1) \Delta$. Likewise, in the partially revealing interval, the price that maximizes profits is $p_{A}-(2 q-1) \Delta$. The hypothesis to be contradicted is then

$$
p_{B}-q \gamma<(1-q)\left(\frac{\eta}{\eta+p_{B}-\gamma}\right) p_{B}
$$

where $p_{B}=p_{A}-(2 q-1) \Delta$ and $p_{B}-q \gamma$ is the maximum profit under nonrevelation, and $(1-q)\left(\frac{\eta}{\eta+p_{B}-\gamma}\right) p_{B}$ is the profit under 
partial revelation.

Since $p_{B}>\gamma$, substituting $\gamma$ for $p_{B}$ on the left-hand side gives us

$$
(1-q) \gamma<(1-q)\left(\frac{\eta}{\eta+p_{B}-\gamma}\right) p_{B}
$$

Rearranging this expression yields $p_{B}<\gamma$, which is a contradiction and proves our result.

- Next, we show that $p_{A}$ won't be in the interval $(\gamma-(2 q-1) \Delta, \gamma+\Delta]$. The information revelation regimes for this interval are the same as above with the exception that the interval $p_{A}-\Delta \leq p_{B} \leq p_{A}-(2 q-$ 1) $\Delta$ is broken into two parts now, namely, there is full revelation with customers following advice when $p_{A}-\Delta \leq p_{B} \leq \gamma$, and the same nonrevealing regime as above when $\gamma \leq p_{B} \leq p_{A}-(2 q-1) \Delta$. Once again, FI $B$ won't set its price so high that everyone purchases $A$, nor will it set its price in the partially revealing region since the above proof holds here as well. Lastly, it is easy to see that the non-revealing region yields higher profits for $B$ than the region in which FI $B$ fully reveals and customers follow the advice (since $p_{B}-q \gamma>(1-q) \gamma$ ), meaning that FI $A$ would realize zero profits.

- Finally, we look for the equilibrium such that $p_{A} \leq \gamma-(2 q-1) \Delta$. Now there are four information revelation regimes: fully revealing such that all customers purchase $B\left(p_{B} \leq p_{A}-\Delta\right)$, fully revealing, such that 
customers follow the advice $\left(p_{A}-\Delta \leq p_{B} \leq \gamma\right)$, partially revealing, $\gamma \leq p_{B} \leq p_{A}+\Delta$, and fully revealing, such that all buy $A$ ( $p_{B} \geq$ $\left.p_{A}+\Delta\right)$. The maximum profits of FI $B$ for both the fully revealing regime in which customers follow advice and for the partially revealing regime comes when $p_{B}=\gamma$ and is equal to $(1-q) \gamma$ (for both). The maximum profits of FI $B$ in the fully revealing all-purchase- $B$ regime is $p_{A}-\Delta$. Therefore, the optimal price for FI $A$ is $p_{A}=\min [\gamma-(2 q-$ 1) $\Delta,(1-q) \gamma+\Delta]$, where the second element prevents FI $B$ from pricing low and giving FI $A$ zero profits.

The profits take the same form as our model with more restrictive reputation costs, namely, $\pi_{A}=q p_{A}$ and $\pi_{B}=(1-q) \gamma-f$. However, there are multiple equilibria that give us this same result, one fully revealing and many partially revealing. The many partially revealing equilibria come from the corner solution that customers who hear $\hat{B}$ always choose $B$. Since FI $B$ realizes zero when the customer is type- $A, \mathrm{FI} B$ is indifferent about what it says to type- $A$, meaning that any probability $y$ of saying $\hat{B}$ must only make the customer strictly prefer product $B$. Using weak dominance (as we do in the text; see Section 4.3.1) gets rid of all partially revealing equilibria (FI $B$ weakly prefers saying $\hat{A}$ to type- $A$ when $p_{B}=\gamma$ ), leaving us with essentially the same equilibrium as in our less general reputation cost model. 


\section{References}

Benabou, R., Laroque, G., 1992. Using privileged information to manipulate markets: insiders, gurus, and credibility. Quarterly Journal of Economics 107, 921-958.

Bester, H., 1998. Quality uncertainty mitigates product differentiation. RAND Journal of Economics 29, 828-844.

Cho, I. K., Kreps, D., 1986. Signaling games and stable equilibria. Quarterly Journal of Economics 102, 179-221.

Darby, M. R., Karni, E., 1973. Free competition and the optimal amount of fraud. Journal of Law and Economics 16, 67-88.

Demski, J., Lewis, T., Yao, D., Yildirim, H., 1999. Practices for managing information flows within organizations. Journal of Law, Economics, and Organization 15, 107-131.

Demski, J., Sappington, D., 1987. Delegated expertise. Journal of Accounting Research 25, 68-89.

Emons, W., 1997. Credence goods and fraudulent experts. Rand Journal of Economics 28, 107-119.

Emons, W., 2001. Credence goods monopolists. International Journal of Industrial Organization 19, 375-389.

Garicano, L., Santos, T., 2004. Referrals. American Economic Review $94,499-525$.

Grossman, S. J., Hart, O. D., 1980. Disclosure laws and takeover bids. 
Journal of Finance 35, 323-34.

Hortacsu, A., Syverson, C., 2004. Product differentiation, search costs and competition in the mutual fund industry: a case study of S\&P 500 index funds. Quarterly Journal of Economics 119, 403-456.

Hotelling, H., 1929. Stability in competition. Economic Journal 39, 4157 .

Laslett, R., Wilsdon, T., Malcolm, K., 2001. The effect of commission based remuneration on financial advice. Financial Service Authority website, http://www.fsa.gov.uk/pubs/other/pol_res1.pdf.

Mailath, G., 1989. Simultaneous signaling in an oligopoly model. Quarterly Journal of Economics 104, 417-427.

Milgrom, P., Roberts, J., 1986. Relying on the information of interested parties. RAND Journal of Economics17, 18-32.

Morgan, J., Stocken, P. C., 2003. An analysis of stock recommendations. RAND Journal of Economics 34, 183-203.

Okuno-Fujiwara, M., Postlewaite, A., Suzumura, K., 1990. Strategic information revelation. Review of Economic Studies 57, 25-47.

Pesendorfer, W., Wolinsky, A., 2003. Second opinions and price competition: inefficiency in the market for expert advice. Review of Economic Studies 70, 417-439.

Pitchik, C., Schotter, A., 1987. Honesty in a model of strategic information transmission. American Economic Review 77, 1032-1036.

Shaked, A., Sutton, J., 1983. Natural oligopolies. Econometrica 51, 1469- 
1484 .

Shavell, S., 1994. Acquisition and disclosure of information prior to sale. RAND Journal of Economics 25, 20-36.

Sirri, E., Tufano, P., 1998. Costly search and mutual fund flows. Journal of Finance 53, 1589-1622.

Wolinsky, A., 1993. Competition in a market for informed experts' services. Rand Journal of Economics 243, 380-398. 